\title{
WORKING WITH A LINGUISTIC CORPUS USING R: AN INTRODUCTORY NOTE WITH INDONESIAN NEGATING CONSTRUCTION
}

\author{
${ }^{\mathrm{a}, \mathrm{c}}$ Gede Primahadi Wijaya Rajeg, ${ }^{\mathrm{b}}$ Karlina Denistia, and ${ }^{\mathrm{c}}$ I Made Rajeg \\ ${ }^{a}$ Monash University, Australia; ${ }^{b}$ Eberhard Karls University of Tübingen, Germany; \\ ${ }^{\mathrm{c}}$ Universitas Udayana, Indonesia \\ a primahadiwijaya@gmail.com; ${ }^{b}$ karlinadenistia@gmail.com; ${ }^{\mathrm{c}}$ made_rajeg@unud.ac.id
}

\begin{abstract}
This paper demonstrates the use of $\mathrm{R}$ for a unified data science in corpus linguistics via a series of corpus-based analyses on Indonesian Negating Construction. The data is based on c17-million word-tokens of an online-news corpus, a part of the Indonesian Leipzig Corpora. We identified that tidak is the most frequent form in our corpus. Next, we found that tak has significantly higher type frequency for negated-predicates with [ter-X-kan] schema compared to tidak; this finding provides a quantitative nuance against a description in an Indonesian reference grammar, stating that (i) in present-day Indonesian tidak is also common to negate ter- related predicates, while (ii) the compulsoriness of tak to negate ter-predicates is a past usage. Lastly, we refine our second finding by applying Distinctive Collexeme Analysis to determine that tak strongly collocates with specific verbs predominantly in the [ter-X-kan] schema compared to tidak; this finding offers a deeper characterisation for tidak and tak.
\end{abstract}

Keywords: $R$ programming language; Quantitative Corpus Linguistics; Distinctive Collexeme Analysis; Indonesian Negating Constructions

\begin{abstract}
Abstrak
Makalah ini menampilkan penggunaan $\mathrm{R}$ untuk pengolahan data holistik dalam kajian Linguistik Korpus. Sebagai contoh, makalah ini melaporkan serangkaian kajian korpus terhadap Konstruksi Negasi di Bahasa Indonesia menggunakan korpus suratkabar daring yang menjadi bagian dari Korpus Bahasa Indonesia Leipzig. Hasil analisis menunjukkan bahwa tidak adalah bentuk yang paling sering digunakan. Selanjutnya, ditemukan bahwa tak memiliki jumlah tipe predikat berskema [ter-X-kan] yang secara signifikan lebih banyak dibandingkan tidak; sudut pandang kuantitatif ini menawarkan asumsi berbeda terhadap pemaparan buku tatabahasa Bahasa Indonesia bahwa (i) tidak dalam Bahasa Indonesia setakat ini juga lazim digunakan menegasi predikat berawalan ter-, sedangkan (ii) kelaziman tak untuk menegasi predikat berawalan ter- hanyalah bagian dari sistem pemakaiannya di masa lalu. Sebagai penutup, tulisan ini memperkenalkan Analisis Koleksem Khas untuk menemukenali bahwa tak, dibandingkan dengan tidak, kerap berkolokasi dengan verba-verba tersendiri yang kebanyakan berskema [ter-X-kan]. Pola kolokasi khas ini menawarkan tataran yang lebih mendalam guna mencirikan tidak dan tak.
\end{abstract}

Kata kunci: bahasa pemrograman R; Linguistik Korpus Kuantitatif; Analisis Koleksem Khas; Konstruksi Negasi Bahasa Indonesia 


\section{INTRODUCTION ${ }^{1}$}

Recent development in quantitative corpus linguistics prospects the growing use of programming language for data science ${ }^{2}$ in processing the linguistic corpus and performing the statistical analyses. $R$ (R Core Team, 2017) is amongst the leading programming platform used for corpus linguistics. ${ }^{3}$ This paper is an introductory note on the use of $\mathrm{R}$ programming language for doing corpus linguistic research with Indonesian corpora. The main motivation for this paper is to share our reflection, especially with our fellow Indonesian linguists, on some of the ideas that we have been learning in conducting corpus linguistics using R. Our aim is to showcase that $\mathrm{R}$ (Section 2.1), and its Integrated Development Environment (IDE) namely RStudio (Section 2.2), can offer a unified state of the art for (i) some of the core text-processing stages of an electronic linguistic corpus, (ii) exploration of a linguistic phenomenon using descriptive and analytical statistics, and (iii) generating reports for communicating the results of data analyses.

As a case study, we explore the usages of Negating Construction ${ }^{4}$ in Indonesian (e.g., tidak, bukan, jangan, etc. (Section 4.1)) (cf., Sneddon, 2006, pp. 56-57; Sneddon, Adelaar, Djenar, \& Ewing, 2010, p. 203). We chose Negating Construction because this is perhaps a less studied phenomenon in Indonesian linguistics, compared to Indonesian morphology or (morpho)syntax, inter alia (but see Kroeger, 2014, for a detailed discussion on bukan 'not'). In addition, just because we take a rather peripheral area of Indonesian linguistics, it does not mean that there is an intention to compromise the depth and breadth of some of the key aspects of $\mathrm{R}$ for performing quantitative corpus linguistics. We will also demonstrate that corpus-based analyses allow us to pinpoint distinctive usage patterns along several analytical dimensions, even between seemingly alternating negations (e.g., tidak vs. tak). The quantitative findings for a given dimension can be used (i) to support, contradict, or offer nuances to the hypotheses in previous description on the use of the negations in Indonesian, and (ii) to generate another new hypothesis to be further tested in future studies. Eventually, through this case study, we aspire to pave a research pathway towards a quantitative usage-based approach to Indonesian.

We will focus on three aspects of the use of the negations and mainly demonstrate how the necessary steps in analysing all these aspects can be done within an integrated $\mathrm{R}$ environment. Firstly, we determine the frequency of occurrence of each negation (Section 4.1). The results will be discussed in relation to previous treatment of the negations in corpus data of different genre (i.e., colloquial Jakarta Indonesian) (cf., Sneddon, 2006, pp. 56-57). Secondly, we provide a quantitative corpus-based analysis to test Sneddon et al's (2010, p. 203) hypotheses regarding the use of tidak 'no, not' and its variant tak 'no, not' in modern Indonesian (Section 4.2). We will determine the extent to which these two negations are associated with the constructional schemas for the negated verbal-predicates we focus on, namely [me-X-kan], [di$\mathrm{X}-k a n]$, and [ter-X-kan]. We measure the association through cross-tabulating the type frequencies (i.e., the number of unique predicates) of each schema immediately following tidak and tak in our corpus (Section 4.3). Finally, we demonstrate the application of Distinctive Collexeme Analysis (DCA) to measure a deeper level of usage potentially distinguishing tidak and $t a k$, namely their verb-specific preferences (Section 4.4). The remainder of this introduction provides a brief overview of what a corpus is (based on Gries, 2009a, pp. 7-11) and ends with pointers to key references on $\mathrm{R}$ for linguistic research.

An electronic corpus as typically used in corpus linguistics broadly refers to a(n) (extensive) collection of machine-readable texts of spoken and written languages. These 
languages are usually gathered from those that are produced in a natural communicative situation, which means that the writers or speakers of the languages have no awareness for their production of the languages with the sole aim of generating a corpus. Machine-readability of a corpus means that it is typically stored in a plain text format and UTF-8 encoding so that it can be processed across computer platforms. The corpus should also be representative and balanced of the language variety, genre, or register.

There are mainly two types of linguistic corpus. The first is a raw corpus. The "raw" in raw corpus means that the corpus consists of only plain texts without any linguistic annotations. Examples of linguistic annotations for a corpus text include (i) part-of-speech (POS) tagging on every word in the corpus, (ii) morphological parsing, (iii) syntactic parsing, among others. The following extract is an example of the raw corpus from an Indonesian short story text. ${ }^{5}$

\#\# [1] "Ketika mereka keluar dari bandara, matahari sudah tenggelam di balik kaki langit
- Darojat dijemput oleh mobil perusahaan obat-obatan, dan Driani di jemput oleh mobil pe
rusahaan perhotelan. Di dalam mobil, Darojat berpikir, jangan-jangan dia tertarik pada D
riani, dan Driani juga berpikir jangan-jangan dia tertarik pada Darojat."

The second corpus type is an annotated corpus. As indicated previously, an annotated corpus contains additional information attached in the corpus, such as POS-tag, lemmas of the word, etc. From the raw corpus example above, we can create a POS-annotated corpus with the Indonesian POS Tagger ${ }^{6}$ (Dinakaramani, Rashel, Luthfi, \& Manurung, 2014), which can be run from $\mathrm{R}$ as well. We designed an $\mathrm{R}$ programming-script for running POS Tagger so that the POS-tag labels are suffixed to the words separated by underscore ("_"). The result of the POSannotation is shown below. The element mereka_PRP, for instance, indicates that the POS Tagger tag the word mereka 'they' as personal pronoun (PRP).

\#\# [1] "Ketika_SC mereka_PRP keluar_VB dari_IN bandara_NN ,_z matahari_NN sudah_MD tengg elam_JJ di_IN balik_VB kaki langit_NN •_Z Darojat_NNP dijemput_VB oleh_IN mobil_NN perus ahaan_NN obat-obatan_NN ,_z dan_CC Driañi_NNP di_IN jemput_VB oleh_IN mobil_NN perusahaa n_NN perhotelan_NN ._Z Di_IN dalam_NN mobil_NN ,_z Darojat_NNP berpikir_VB , z jangan-ja ngan_RB dia_PRP tertarik_JJ,VB pada_IN Driani_NNP, z dan_CC Driani_NNP juga_RB berpikir _VB jangan-jangan_RB dia_PRP tertarik_JJ,VB pada_IN Darojat_NNP •_z"

Several introductory textbooks on $\mathrm{R}$ for quantitative corpus linguistics have appeared in recent years (e.g., Baayen, 2008; Desagulier, 2017; Gries, 2009a, 2009b, 2013c; Levshina, 2015). As fellow learners, it is our hope that the interested readers, especially within the Indonesian linguistics circle, will dive into these references for further collaboration in conducting (corpus) linguistic research with $\mathrm{R}$.

\section{R AND R STUDIO IN A NUTSHELL}

\subsection{R environment and $R$ functions}

$\mathrm{R}$ is an open-source programming language for statistical computing and data visualisations. It can be downloaded for free from $C R A N^{\gamma}$ (i.e., the comprehensive $R$ archive network) and is available for Windows, Mac (OS X), and Linux. This paper will show that $\mathrm{R}$ is a powerful resource, not only for statistical analyses but also for one of the central tasks for corpus linguistics, namely text processing.

As an open-source software, $\mathrm{R}$ emerges into a community of practice where anyone can contribute to the development of $\mathrm{R}$ functionalities. $\mathrm{R}$ has its main conference, namely $u s e R,{ }^{8}$ and a dedicated journal, The $R$ Journal. ${ }^{9}$ There is also an R-related blog called $R$-bloggers ${ }^{10}$ that is the hub for $\mathrm{R}$ users to exchange and share updates, including tutorials, for doing data science 
with R. Another excellent place to look for solutions to R-related issues is Stack Overflow, ${ }^{11}$ among others. Thus, there are a lot of online sources through which one can learn about $\mathrm{R}$.

Upon opening R, users will face a console (cf., Figure 1 below), which prints out the information about the $\mathrm{R}$ version installed and any other relevant information about the $\mathrm{R}$ statistical projects, including how to cite it. Following this introductory information is an empty console. It expects the users to type a command-input/programming code after the larger-than symbol ( $>$ ) called prompt line. After typing the command, users then hit "Enter" for $\mathrm{R}$ to perform the specified command. The snippet in Figure 1 shows simple arithmetic operations as commands for R to execute. They are addition (i.e., $1+1$ ) and multiplication (i.e., $2 * 2$ ).

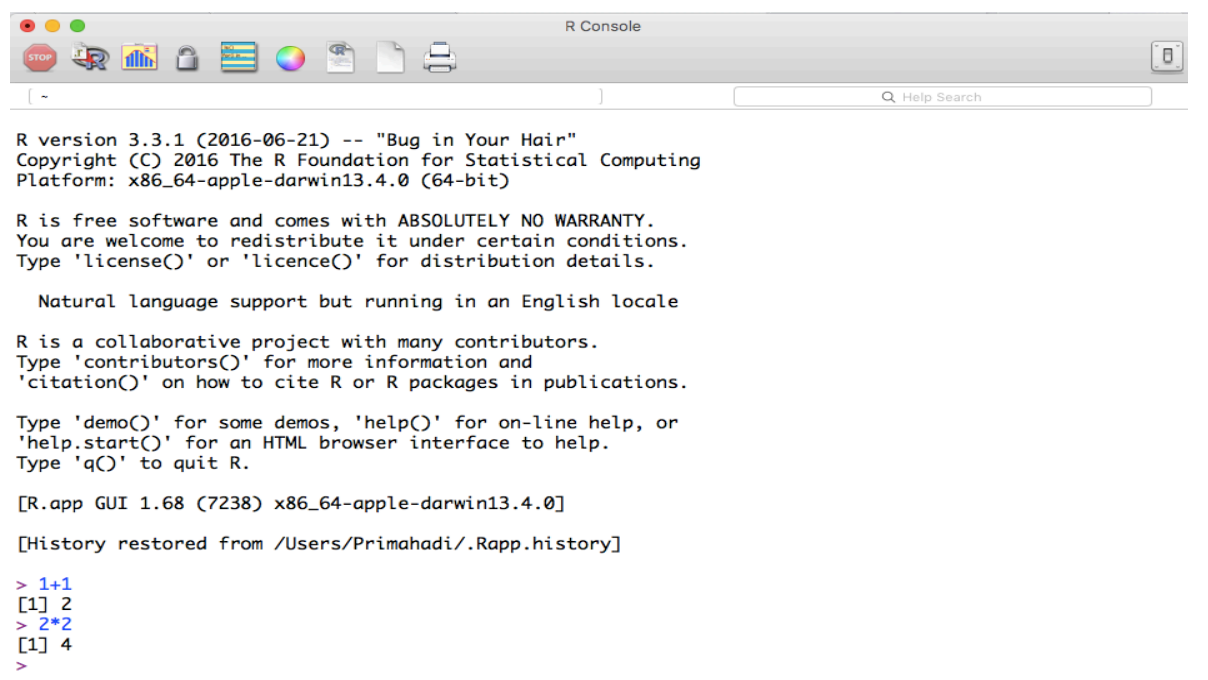

Figure 1 Snippet for $\mathrm{R}$ console (on Mac OS X)

Two or more commands can be executed simultaneously in one line. Each of these commands should be separated by semicolons “;”. This is exemplified below. ${ }^{12}$

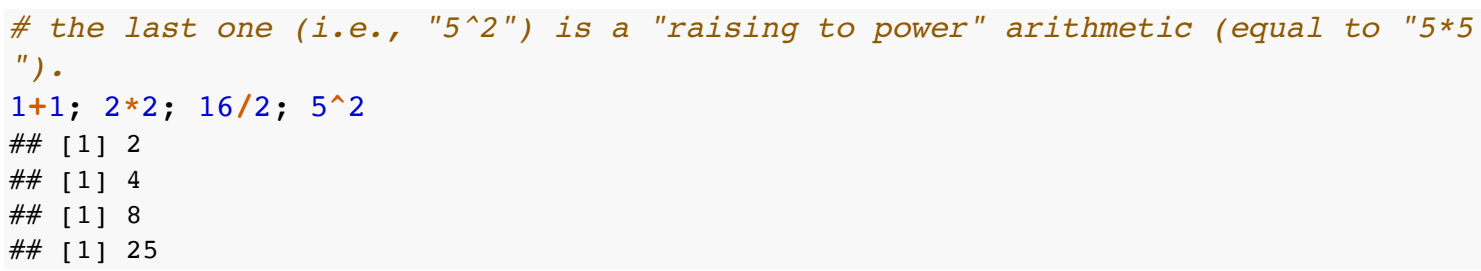

The number in square brackets (e.g., [1]) indicates index number of the output element(s) of a given command. Each of the above commands produces only a single output, hence the 1 in the brackets.

$\mathrm{R}$ of course can do more than just simple arithmetic. In learning $\mathrm{R}$ as a programming language, one needs to know the language used to command $\mathrm{R}$ to perform certain operations. The command is essentially in the form of functions and their required argument(s). The basic schema of an $\mathrm{R}$ function is name.of.a.function (argument $\mathrm{A}=\ldots$, argumentB $=\ldots, \ldots$ ) where two or more of the specified arguments are separated by commas. The argument(s) to a function indicates "(i) what the instruction to be applied to and (ii) how the instruction is to be applied to it" (Gries, 2009a, p. 24). The following example with sqrt() function shows an operation to derive the square root of a number (i.e., 8); sqrt () requires only one argument that is by default labelled as $\mathrm{x}$. 


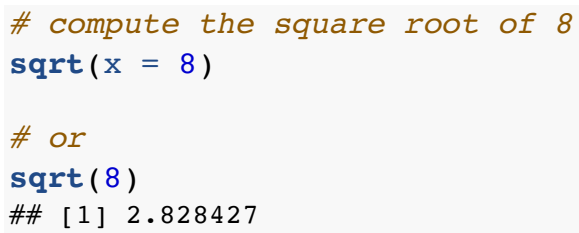

Argument label(s) of a given function, such as the $\mathrm{x}$ argument for sqrt(), can be left out in the code provided that we remember to supply the argument(s) in the exact order as required by the function. For instance, input for argument $x$ must come before input for argument $y$, etc. A safer practice is to spell-out the specified arguments when a function has many labelled arguments.

We can store, or assign, the output of the above command into a data structure for later use. To assign output(s) of a command, we use the arrow symbol <- (i.e., the combination of a less-than sign < and a minus -). To instruct $\mathrm{R}$ to print out or output the assigned value to the console, just type the name of the data structure we use to store the results and then hit "Enter". These operations are shown below.

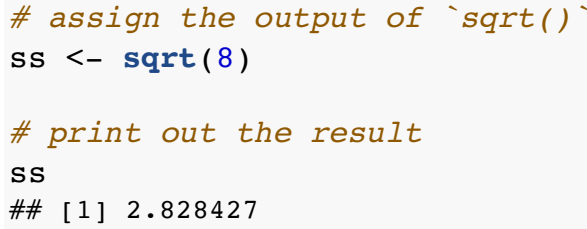

The stored output can be used for further operation. For instance, we could round the floating points of the result of the square root of eight by means of round(). We can use the ss data structure as one of the input arguments for round() (i.e., the $\mathrm{x}$ argument, which is the number to be rounded). Another argument of round() is digits, specifying the number of floating points to keep. ${ }^{13}$ Then, the output of round() can be stored into another data structure that we may call ss.rnd.

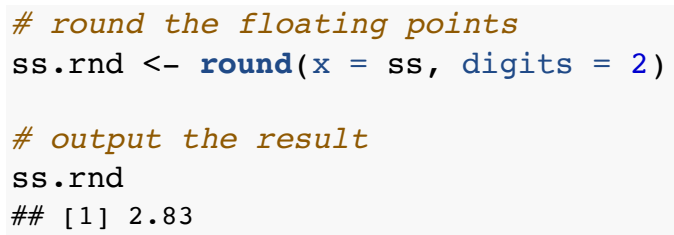

The base installation of $\mathrm{R}$ has a variety of functions for a great number of data science processes, including text processing and statistical analyses. There are also functions, and data, that come with the so-called $\mathrm{R}$ packages. $\mathrm{R}$ packages are features that enhance the capability of the base R; all R packages are also available for free. The packages need to be installed and loaded when opening $\mathrm{R}$ so that we can utilise the functions from the packages. This paper will illustrate how data processing in relation to corpus linguistic analysis can be performed by functions from the basic installation of $\mathrm{R}$.

\subsection{Unified data science in RStudio with $R$ Markdown}

This section provides a brief tour on the integrated environment for $\mathrm{R}$ programming, namely RStudio, which is also available for free. ${ }^{14}$ One of the hallmarks of RStudio is its authoring feature called $R$ Markdown $^{15}$ (Wickham \& Grolemund, 2017, pp. 423, 469, 479), which is an integral part of the $R$ Notebook interface. ${ }^{16} \mathrm{R}$ Markdown notebook is a platform to (i) write the programming-code for conducting our data processing and analyses, (ii) output in-line results of the programming for the analyses, and simultaneously (iii) write-up the narratives for the results. 
R Markdown support a range of output formats, including MS Word. ${ }^{17}$ Put it simply, we can write papers, theses, or even books, with the analysis of a phenomenon via $\mathrm{R}$ Markdown in RStudio; nearly every single word in this paper, the workflow for analysing the Negating Construction, and the results are all written and processed via an R Markdown notebook in RStudio. Figure 2 shows a snippet of the RStudio interface of an R Markdown notebook for the writing of this paper ${ }^{18}$ (upper panel); it also shows the R-console window (lower panel) where the programming codes are normally executed.

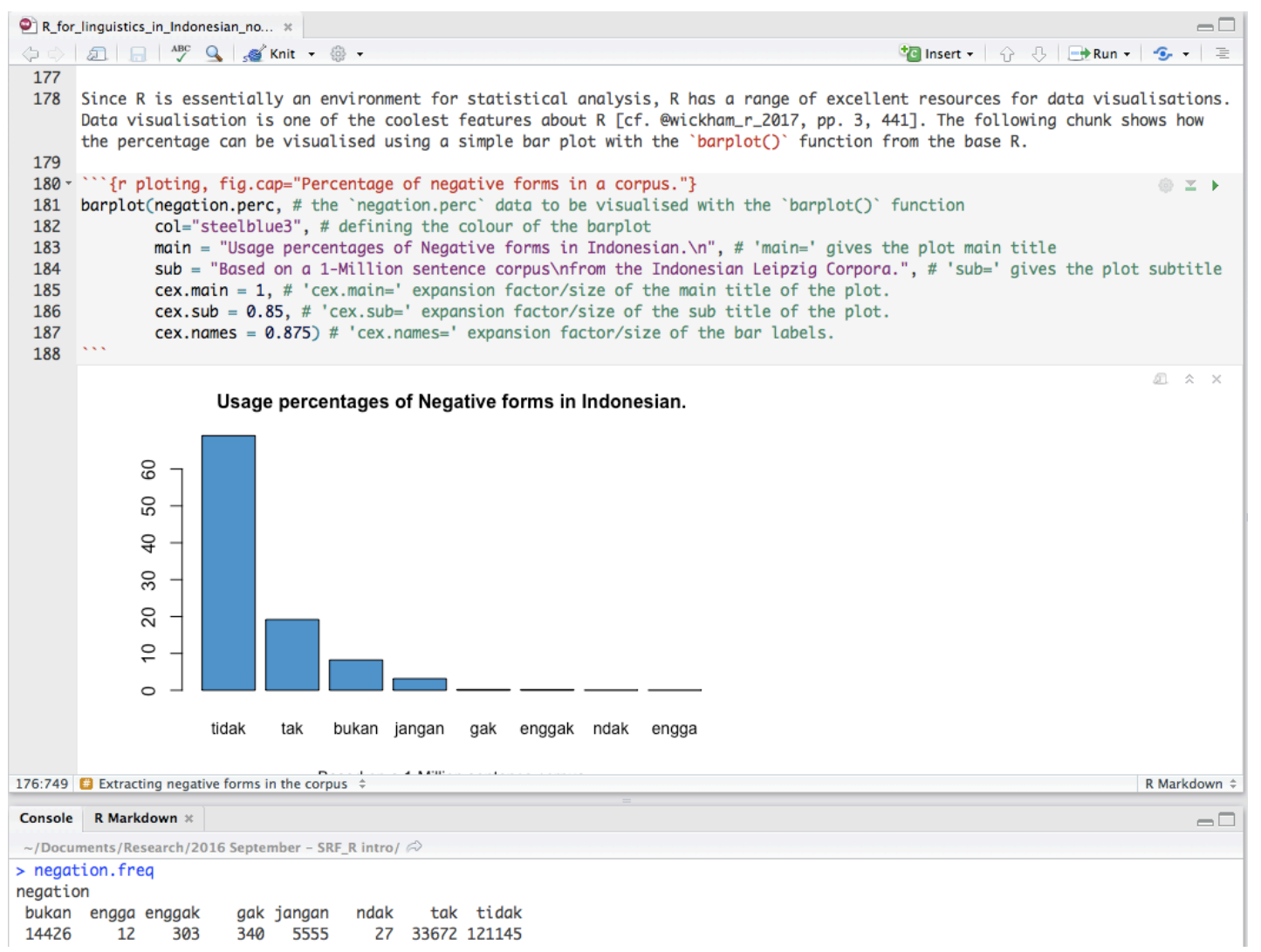

Figure 2 RStudio snippet for R Markdown interface (top window) and R console (bottom window)

The grey-shaded area (starting from line 180 to 188) in the snippet above is called the code-chunk where we insert the $\mathrm{R}$ codes to perform a given operation. We have seen this codechunk in Section 2.1 when discussing $\mathrm{R}$ functions. The area below the code-chunk may contain outputs of a specific operation. In the snippet above, it is illustrated with the output of a plotting/visualisation command (cf., Figure 3 below). Other typical in-line output include (i) tables (e.g., Table 1 in Section 4.1 below), (ii) numbers as we have seen before with round() and sqrt(), or (iii) character strings/texts (cf., Section 3.2). The narratives of the whole document are written mainly in the white area as plain text; in Figure 2 above, it is the area above the code-chunk (i.e., starting from line 177).

The snippet of the $\mathrm{R}$ Markdown interface above hopefully helps readers to form an overall picture of what we mean by performing a unified, well-tailored data science with $\mathrm{R}$ in RStudio. This spans across writing the programming codes for processing and analysing the data through to writing up and reporting the results within one environment. Such unified environment then allows us to generate the so-called reproducible analyses and report (cf., Flanagan, 2017). It means that all analytical steps, such as data processing, programming codes, 
and their outputs, are available in the form of an R Markdown document. In this way, people having access to the $\mathrm{R}$ Markdown document and the dataset can reproduce what we do with the aim of obtaining the same results. Moreover, R Markdown considerably reduces pain from having separate files for the research notes, datasets, results of quantitative analysis from a statistical software, and another software to write-up the results. Practically, RStudio and R Markdown help the "future-us" to manage and recall all this complex information. In the next section, we flesh out this unified process of data analysis in R through a corpus linguistic study.

\section{EXPLORING CORPUS DATA WITH R}

This section demonstrates the processing of corpus data in $\mathrm{R}$ for corpus linguistic exploration on the Negating Construction in Indonesian (cf. Section 4); our analytical workflows are presented in the embedded code-chunks. For this paper, we use one corpus file, that is the ind_newscrawl_2012_1M-sentences.txt, out of the whole collection of the Indonesian Leipzig Corpora (Biemann, Heyer, Quasthoff, \& Richter, 2007; Goldhahn, Eckart, \& Quasthoff, 2012). Leipzig Corpora is a collection of sentence-based corpus texts with number in each sentence; they can be downloaded for free. ${ }^{19}$ The corpus files in the Indonesian Leipzig Corpora are raw corpus since there are no additional annotations, such as POS-tag. The sources of the text in Leipzig Corpora are mainly online newspapers, randomly scrapped webpages, and Wikipedia.

\subsection{Loading corpus files into $R$}

The following code-chunk shows how a corpus file is loaded into $\mathrm{R}$ for further processing. The function to read-in a file containing texts, such as a corpus, is scan().

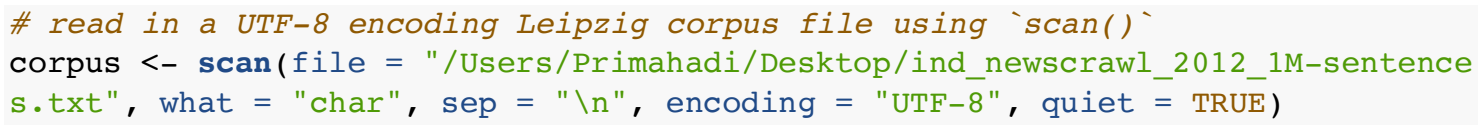

For our purpose, scan() requires at least three of its arguments to be specified. The first argument is file, which is specified with input of the name of the corpus file, preferably with the full directory path; argument inputs of the type text/string, such as a name of a corpus file, should be quoted with double-quote or single quote. The second argument is what, which indicates the type of the file to be loaded; in this case, the corpus is the type of character; hence the "char" value. The last argument is sep that specifies how the text file is separated; in this case, each sentence in the Leipzig corpus is separated by newlines, hence the " $\backslash \mathrm{n}$ " value of sep. If the corpus file is in UTF-8 encoding, it is important to specify the encoding argument as well. Meanwhile, the quiet $=$ TRUE parameter is optional to suppress printing message about the total number of lines read-in from the corpus.

We can then inspect the values of the character vector corpus containing the loaded corpus. One of the possible operations is to find out the number of elements, in this case sentence lines, in the corpus. This can be done with length() with corpus as its main argument.

The output of length () indicates that the loaded Indonesian Leipzig corpus consists of $1,000,000$ million elements representing sentences, which is obvious from the name of the corpus file. The corpus variable represents one of the basic data structures in $\mathrm{R}$, namely a vector (cf., Gries, 2009b, pp. 66-71). A vector consists of "one-dimensional, sequentially ordered 
sequences of elements (such as numbers or character strings (such as words))" (Gries, 2009b, p. 66). In Section 2.1, we have dealt with numeric vectors in the introduction to few $\mathrm{R}$ functions with sqrt() and round(); we will see below other types of data structures in R, namely list and data frameltable. We can check whether or not corpus is a vector using the following code.

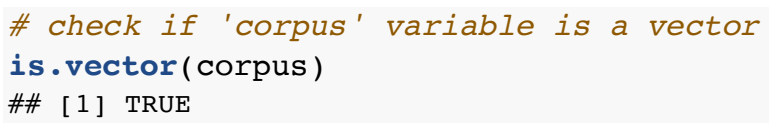

The code below checks the type of elements contained in the corpus vector.

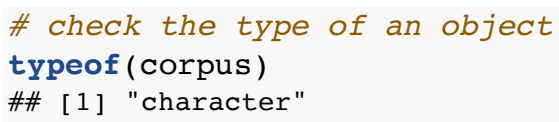

To subset/access parts of the elements in a vector (or the other data structures), we use square brackets [ ]. The following code-chunks illustrate few possible scenarios for subsetting elements (i.e., sentences) in the corpus vector. The first one is as follows.

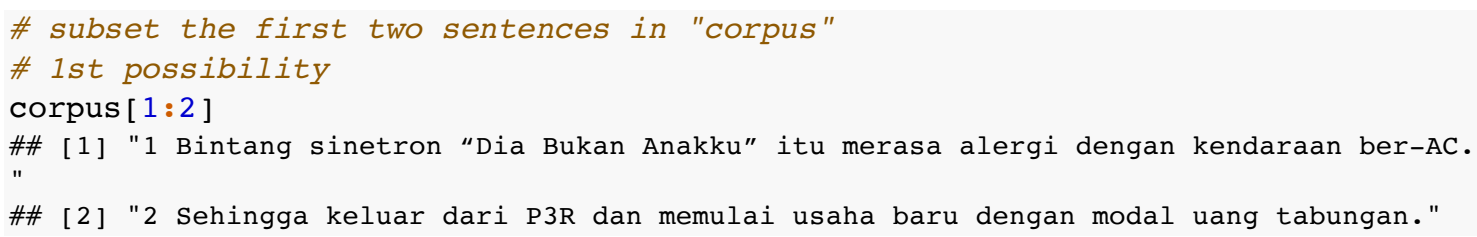

The second alternative for the above code is as follows.

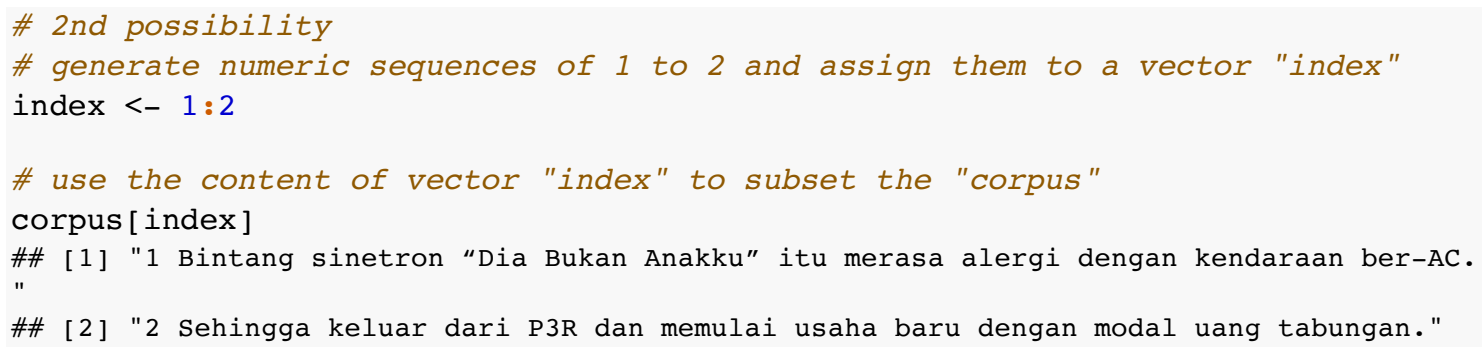

Lastly, the following code shows how to subset vector elements in a mixed sequence. For instance, subsetting the second, seventh, and ninth to eleventh elements of the corpus. We use the $\mathrm{c}$ () function to concatenateljoin several elements (e.g., the subsetting number-indices) into the index vector.

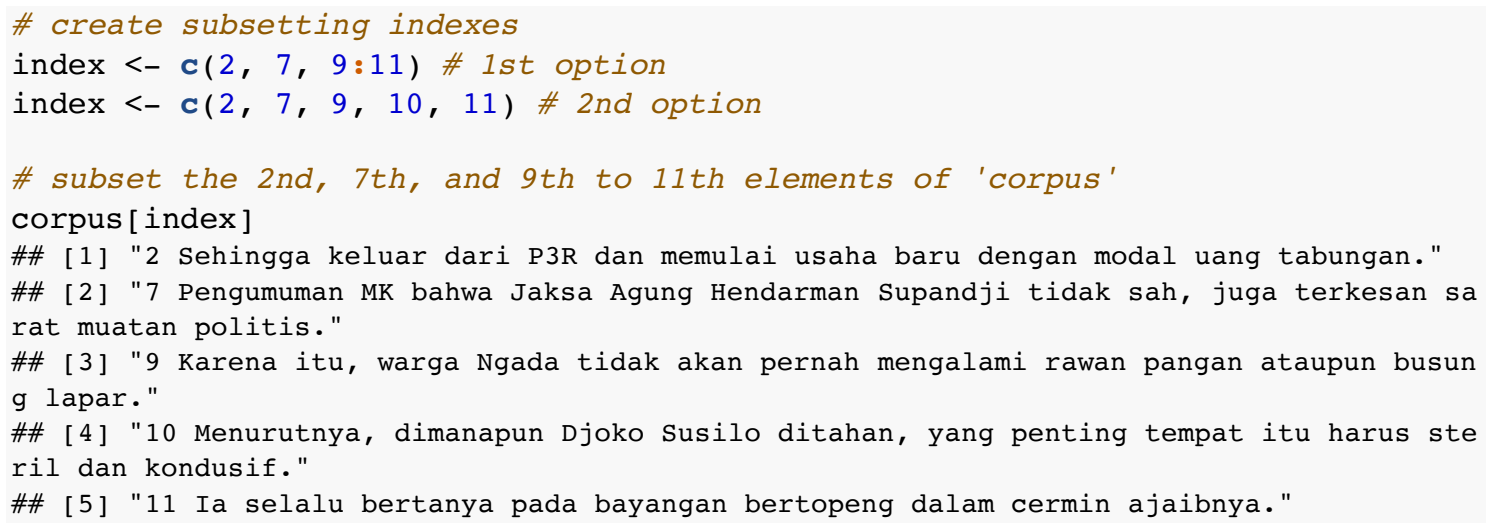

The output shows that we do get sentences number 2, 7, 9, 10, and 11; the numbers in the square brackets show that for the above command, there are five sequential outputs (hence, [1] to [5]). 


\subsection{Determining the size of a corpus}

Before coming to our target construction, we would like to demonstrate how one can determine the total size (in a word-token) of our corpus, that is how many words are there in a one-million sentence corpus? To do that, firstly, we need to tokenise, or split, character strings, such as sentences, into individual words. The relevant function for this purpose is strsplit().

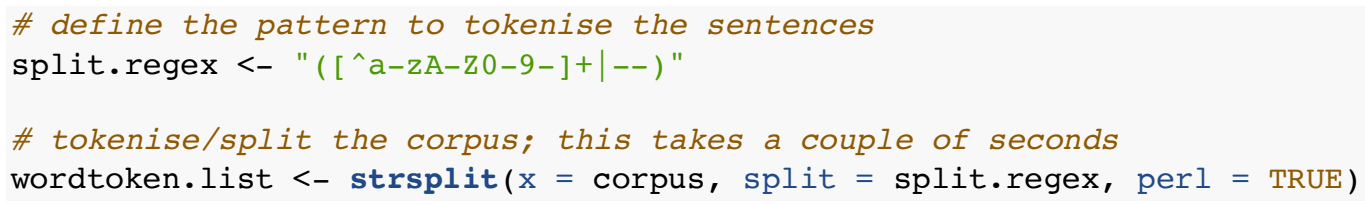

The $\mathrm{x}$ argument of strsplit () requires the texts/character strings to be split; in this case, it is our corpus stored in the vector corpus. The split argument specifies a pattern for how the texts to be split; for this purpose, we use a powerful pattern-matching procedure called regular expressions (henceforth, regex) (Gries, 2009a, pp. 79-99; Sanchez, 2013; Wickham \& Grolemund, 2017, pp. 200-207). Then, the perl argument is set to TRUE to indicate that we use the $\operatorname{Perl}^{20}$ compatible regex.

The regex we use to split the sentences is "( [^a-zA-z0-9-]+|--)" (cf., Gries, 2009a, p. 151). This regex is designed to capture and split characters that are not part of a word:

split at any one or more (i.e., the "+") characters that are (i) NOT (i.e., the caret "^" inside the square brackets) parts of alphanumeric character classes (i.e., "[^a-zA-z0-9]") and (ii) NOT hyphen ("-", hence "[^a-zA-z0-9-]"), as to maintain reduplicated tokens, such as anak-anak 'children', (iii) OR (i.e., the pipe "| ") split at characters that are dashes ("--").

The wordtoken.list object contains the results of strsplit(), which are in the form of a data structure called list.

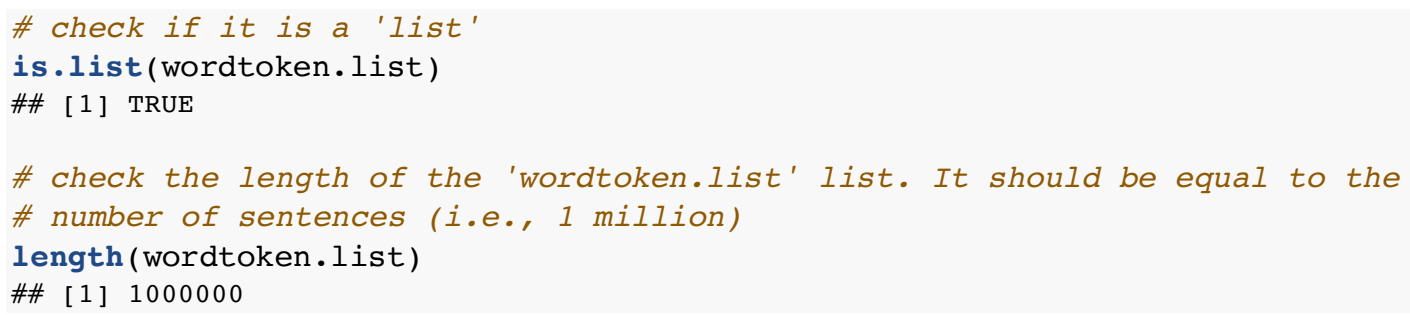

A list is a very versatile data structure since it can contain heterogeneous data structures (cf., Wickham \& Grolemund, 2017, p. 302). For instance, the first element of a list can be a data frame while the other elements can be (numeric or character) vectors, or even lists. We will not deal with this in details here. However, it suffices to mention that each (one-million) element of the wordtoken.list contains character vectors of words derived from splitting up each (onemillion) sentence. The following codes subset two specific elements within the wordtoken.list to show how a list looks like when it contains the split character-vector elements.

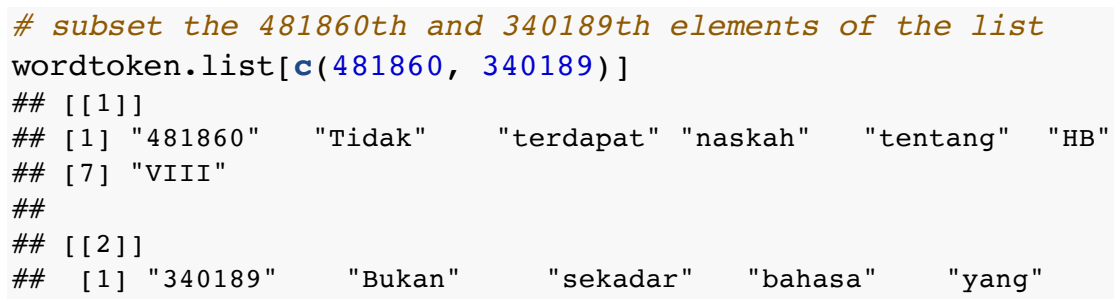




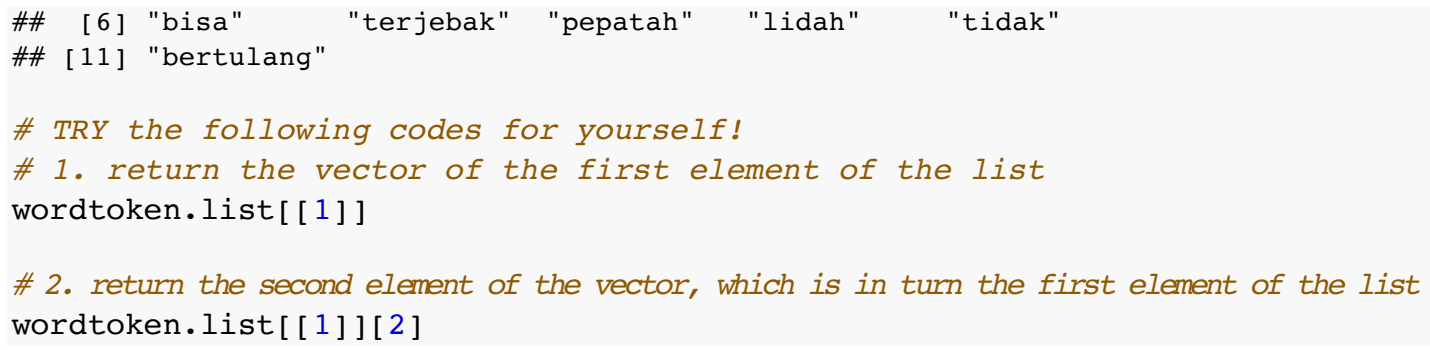

For the purpose of counting all the tokenised words in the corpus, it is more manageable to turn the wordtoken. list into an atomic vector (cf. Wickham \& Grolemund, 2017, p. 293). The vector then contains elements of all words in the corpus. The relevant function for this operation is unlist() with a list as the input data; unlist() turns the complex list into an atomic vector.

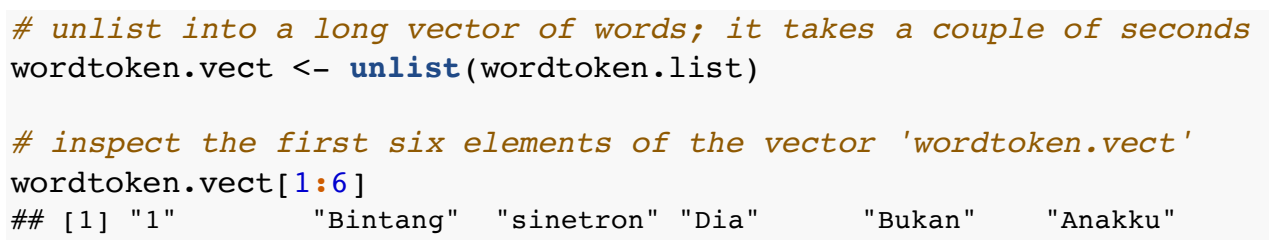

The next step is to count the number of words in the corpus by using length() and feeding the wordtoken. vect as the input-argument.

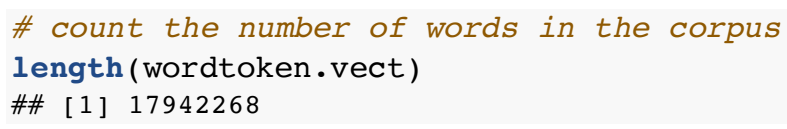

The value indicates that in our corpus file of one-million sentences, there are 17,942,268 million word-tokens; the words consist of one or more, case-insensitive, alphanumeric character, including hyphen (-), separated by whitespace. In order to get the number of unique word-types, we need to lowercase the words using tolower(), before feeding them into unique() then length (), as shown in the following codes.

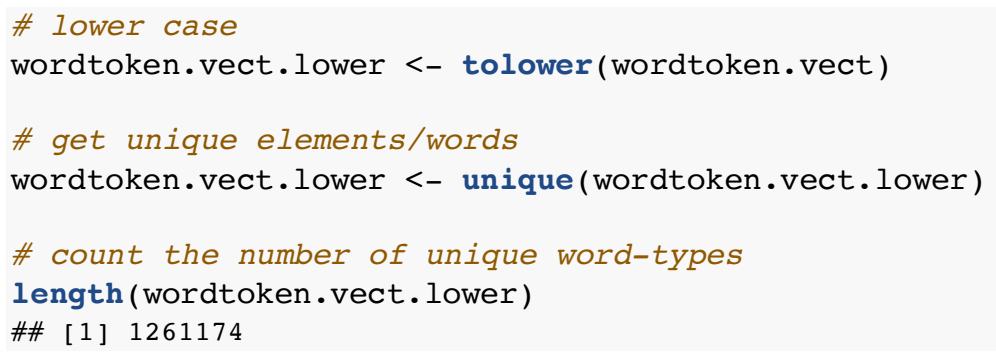

The output tells us that the 17,942,268 million word-tokens of the corpus are made up of $1,261,174$ million word-types.

\section{EXPLORING THE INDONESIAN NEGATING CONSTRUCTIONS}

\subsection{Extracting the negating forms}

We now proceed to obtain the occurrence of a set of Negating Constructions in Indonesian and generate their frequency of occurrences (cf., below). The constructions include the following forms: bukan, enggak, engga, gak, jangan, ndak, tidak, tak. The forms enggak, engga, and gak are attested as variants at the level of pronunciation; they occur in high frequency in Colloquial Jakarta Indonesian, especially enggak (cf., Sneddon, 2006, pp. 56-57). Another colloquial form 
is $n d a k$, which is potentially a variant of the formal tidak. Tak, which is suggested to have "a literary flavour for most Indonesians", is considered another variant of tidak (Sneddon et al., 2010, p. 203). Jangan is a negation in an imperative sentence closely resembling English 'don't' while bukan 'not sth. (but rather sth. else)' typically negates nouns (cf., Sneddon et al., 2010, p. 334). All these forms will also be retrieved using regex that we have seen in Section 3.2 when we perform the tokenisation of the words (in the split argument of strsplit()).

We design the following regex to extract the potential match for each negative form:

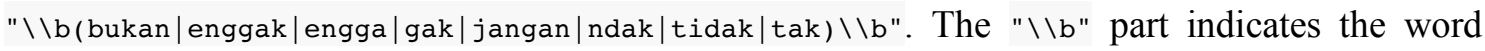
boundaries (Gries, 2009a, p. 128); in this case, we want the form tak, for instance, to be extracted as such (i.e., tak), rather than as part of a larger word (e.g., botak 'bald'). The pipe "I" indicates alternative. The round brackets "() " capture the sequence of the character strings (e.g., "bukan") as a unit/group of alphabetic characters.

The following code-chunk shows the whole process of extracting the negating forms from the corpus. The relevant functions are gregexpr() and regmatches (): the former outputs the starting and final character-position of the searched pattern, including its length (in character), meanwhile the latter extracts the relevant forms based on the output of gregexpr ( $)^{21}$. In Section 4.2 below, we will see how the use of these two functions in the following code-chunk can be adjusted and re-cycled for a slightly different purpose, namely finding the negated predicates immediately following the negations.

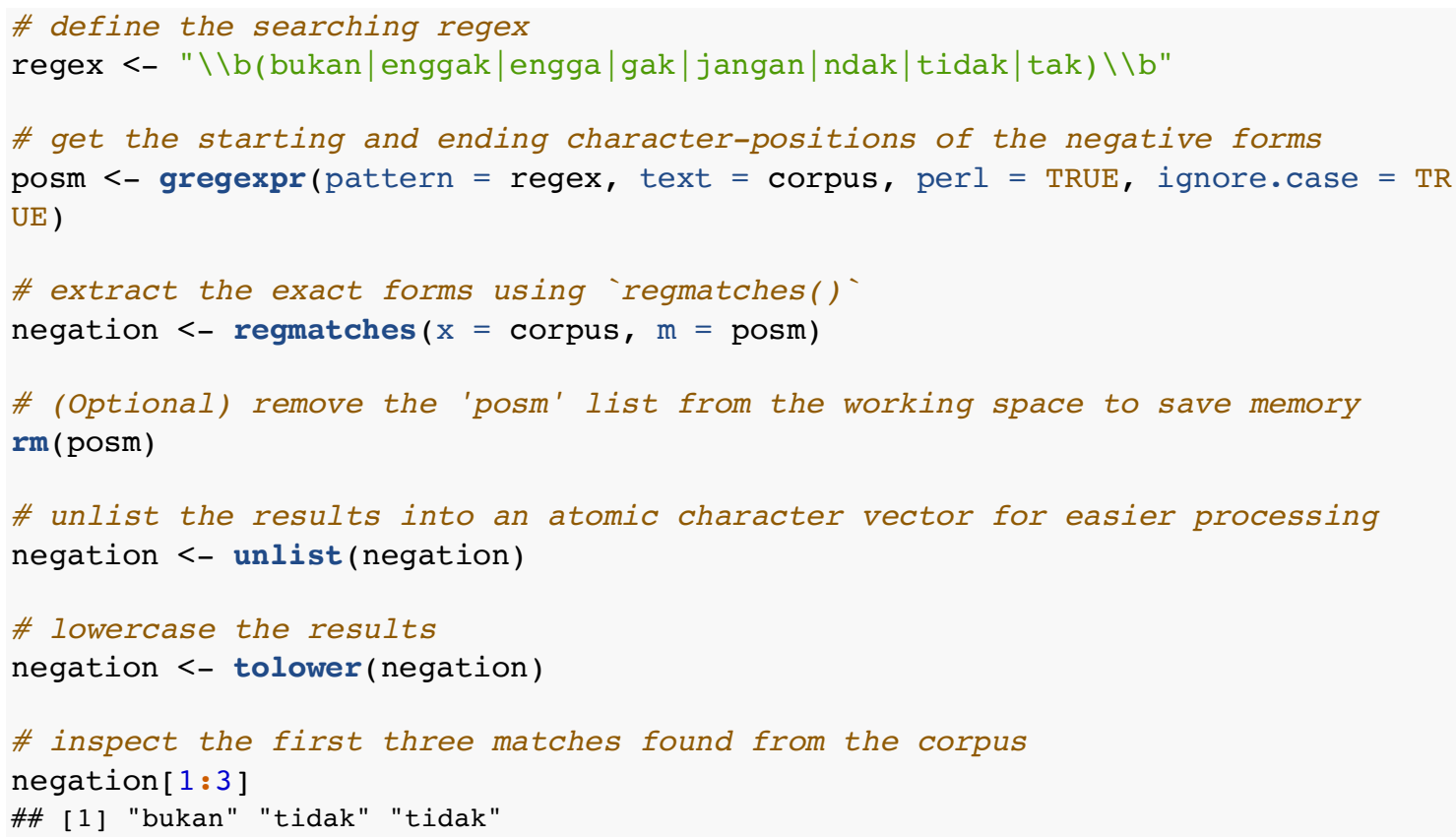

After retrieving the negating forms, one may proceed with generating a frequency list of all these forms. This analysis can be performed with table() as shown below.

\# create frequency list of the negative forms

negation.freq <- table(negation)

The frequency list can then be sorted using sort() with its decreasing argument is set to TRUE.

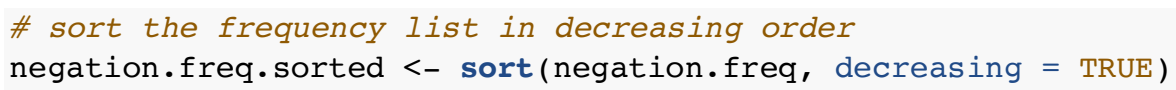




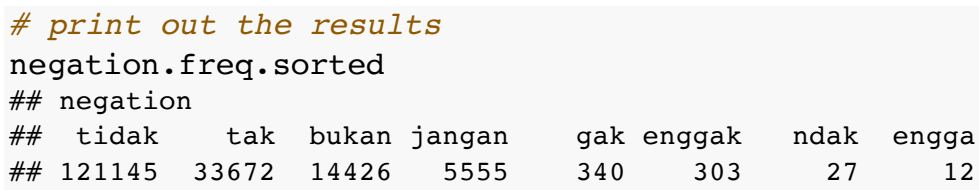

The outputs of table() above are raw frequency counts/tokens of the forms. It would also be good to provide the relative frequency of these forms in the form of proportion or percentages so that the forms can be compared along the same scale (cf., Janda \& Lyashevskaya, 2013, p. 224). The following chunk shows how the raw frequencies can be converted into (i) proportions, using prop.table(), or (ii) percentages, by multiplying the results of prop.table() with 100.

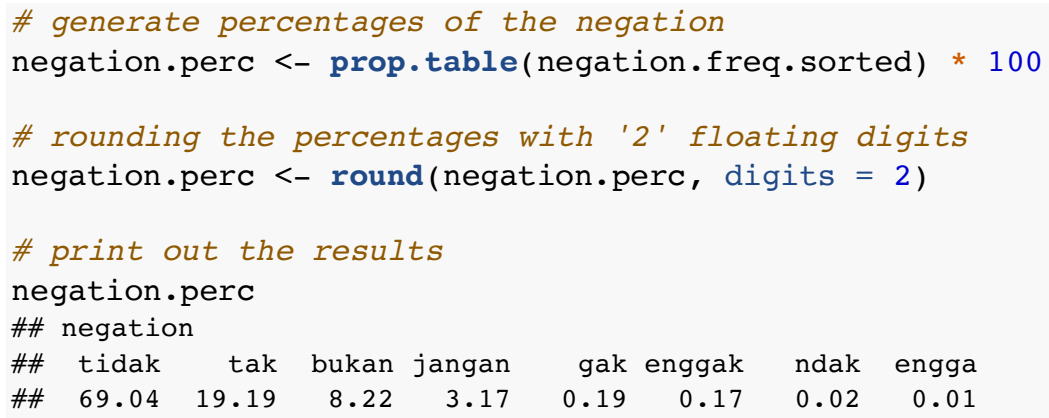

A basic insight that can be learnt from the relative frequencies is the extent to which a given negating form is used in a one-million sentence corpus of Indonesian online news. The colloquial forms, namely gak, enggak, engga, and ndak, occur much less frequently, which could be expected given that they have been found to be highly frequent in Colloquial Jakarta Indonesian, especially in the conversation and interview recordings (cf., Sneddon, 2006, p. 57). In terms of usage property, the usage proportion of the negation can indicate which variants are relatively more common of a given corpus genre (i.e., online news). Tidak is the common negative form used in the corpus, taking up $69.04 \%$ of the total occurrences of the extracted negating forms. This could be explained, in part, by the more formal setting of news genre, which would require the use of more formal variant (i.e., tidak).

Since $\mathrm{R}$ is also essentially an environment for data visualisation, $\mathrm{R}$ has a range of resources for visualising results of statistical analyses (cf., Wickham \& Grolemund, 2017, pp. 3, 441). The following chunk shows how the percentages of the negating forms (stored in negation.perc) are visualised using a bar plot with barplot() from the base R (cf., Figure 3).

barplot(negation.perc, col = "steelblue3", cex.main $=1$, cex.names $=0.7, y l i m$ $=\mathbf{c}(0,100)$, main = "Usage percentages of negating forms in Indonesian.") 
Usage percentages of negating forms in Indonesian.

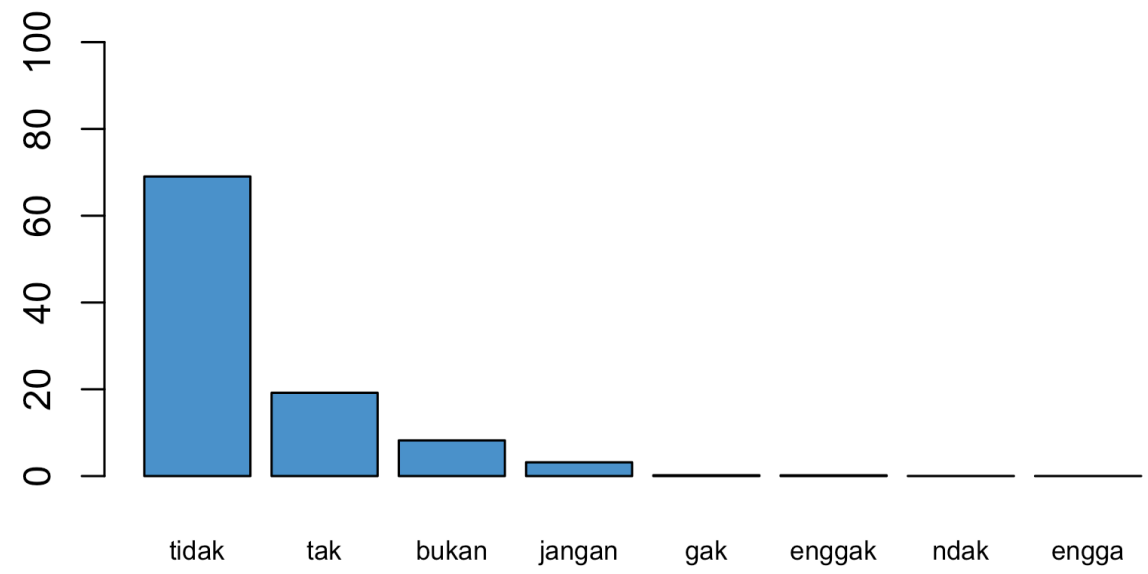

Figure 3 Percentages of negating forms in 'ind_newscrawl_2012_1M-sentences.txt' corpus of the Indonesian Leipzig Corpora

The col argument of barplot() can be filled with character name for the bar colours. The main argument is filled with texts for the main title of the plot. The cex.main and cex.names arguments respectively control the character expansion factor for the size of the main title and the bar labels. The ylim argument specifies the limit of the $y$-axis (i.e., the vertical axis) that ranges from zero to maximum 100, representing percentages of the negating forms.

Another remarkable feature of $\mathrm{R}$ Markdown notebook is that we can generate an in-line table as part of our report. For that purpose, we need to turn the results stored in negation.perc vector into a table format called data frame with the following codes; the relevant function to generate a data frame from a set of atomic vectors of the same length is data.frame().

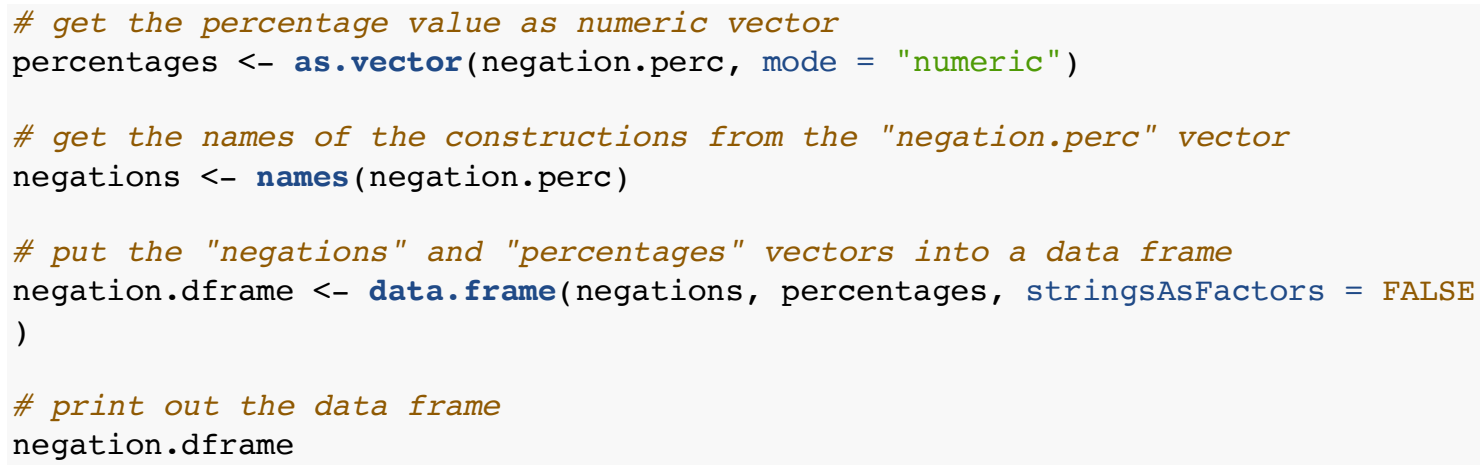

Table 1 The data frame of percentages of the Negating Constructions

\begin{tabular}{llr} 
& negations & percentages \\
\hline 1 & tidak & 69.04 \\
2 & tak & 19.19 \\
3 & bukan & 8.22 \\
4 & jangan & 3.17 \\
5 & gak & 0.19 \\
6 & enggak & 0.17 \\
7 & ndak & 0.02 \\
8 & engga & 0.01
\end{tabular}


Up to this stage, we are hoping that we have been able to demonstrate a simple, yet hopefully elegant, example of how a series of data processing into gaining insight about a linguistic phenomenon can be done in a unified fashion in R. They include loading the corpus text, extract the occurrences of the linguistic phenomenon of interest (with regexes), perform one of the core corpus linguistic analyses (viz. frequency list), and finally communicate the results, via a table (e.g., Table 1) and a plot (e.g., Figure 3). The remainder of this paper provides more intriguing examples by (i) recycling the searching procedures that we have performed, with few additions, and (ii) generating further theoretical insights into the use of the negations using a set of analytical statistics.

\subsection{Extracting collocational patterns of the Negating Constructions}

This section takes a step further in exploring the usage of the Negating Constructions in Indonesian. We focus on the collocational patterns of the two most frequent negation forms in our corpus, namely tidak and tak. The collocational patterns are restricted to the fillers of the negated predicates immediately to the right of these negation forms. The constructional schema of this collocation can be represented as [tidak/tak + PREDICATES]. As an illustration, the predicate-fillers to be explored are potential verbal predicates in three constructional schemas, namely [me-X-kan], [di-X-kan], and [ter-X-kan]. The "Xs" may stand for the root forms of the verbs; the prefixes indicate different grammatical voices: active (me-), (dynamic) passive (di-), and (stative) passive (ter-) (cf., Arka, 2010, for the discussion on dynamic and stative passive in Indonesian); the -kan suffix is intended to ensure the predicates are (di)transitive verbs.

The searching procedures and related functions at the beginning of Section 4.1 will be reused to help readers internalise how a series of similar methods can be slightly tweaked for different analytical purposes. The key variation here is mainly on the regex design to be used to extract the collocation. For instance, the regex that we designed to search for the immediate negated-predicates for tidak is $" \backslash \backslash b(?<=\operatorname{tidak} \backslash \backslash \mathrm{s})((\operatorname{ter}|\mathrm{di}| \operatorname{me})[a-z]\{3\} k a n,) \backslash \backslash b "$. What the regex does is as follows:

search the occurrence of words that begin with ter, di, or me prefixes (i.e., "(ter $\mid$ di $\mid$ me) ") followed by at least three or more alphabetic characters (i.e., " $[a-z]\{3$,$\} "), and that are$ ended with $k a n$ (i.e., "kan"). These words have to be immediately preceded by tidak followed by a white space (i.e., "tidak \\"); but the positive lookbehind assertion (i.e., the " (?<=)"

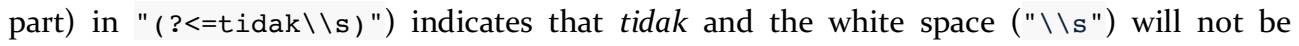
captured/extracted in the output, hence only the negated predicates.

The same regex design will be used to search for the negated-predicates for tak by replacing "tidak" with "tak" in the regex above.

One thing to keep in mind is that, based on our intuition, we assume that the three constructional schemas restriction above and the regex design will return mostly verbs, but not the other word classes, or even other verbs, that happen to contain ter-/di-/me- and -kan strings. For instance, teriakan 'a shout(ing)', based on teriak 'to shout', will be filtered out by the regex because there are only two alphabetic characters in this word following the prefix ter-, namely $i a$, before followed by the suffix -kan. Similar case holds for verbs. For example, memakan (from makan 'to eat') and ditekan 'to be pressed' (from tekan 'to press') will not be captured by the regex. In this case, the results of analyses in relation to the collocational data, as reported in Section 4.3 and Section 4.4, are restricted to the potential verbs with the specified three constructional schemas as captured by the regex design. Future study can generate different 
regex design to capture all potential $m e-$, $d i$-, and ter-verbs, which may include the suffix -kan and $-i$, negated by tidak and tak. The following codes show the processes to extract the negated predicates for tidak. The top-10 results are presented in Table 2.

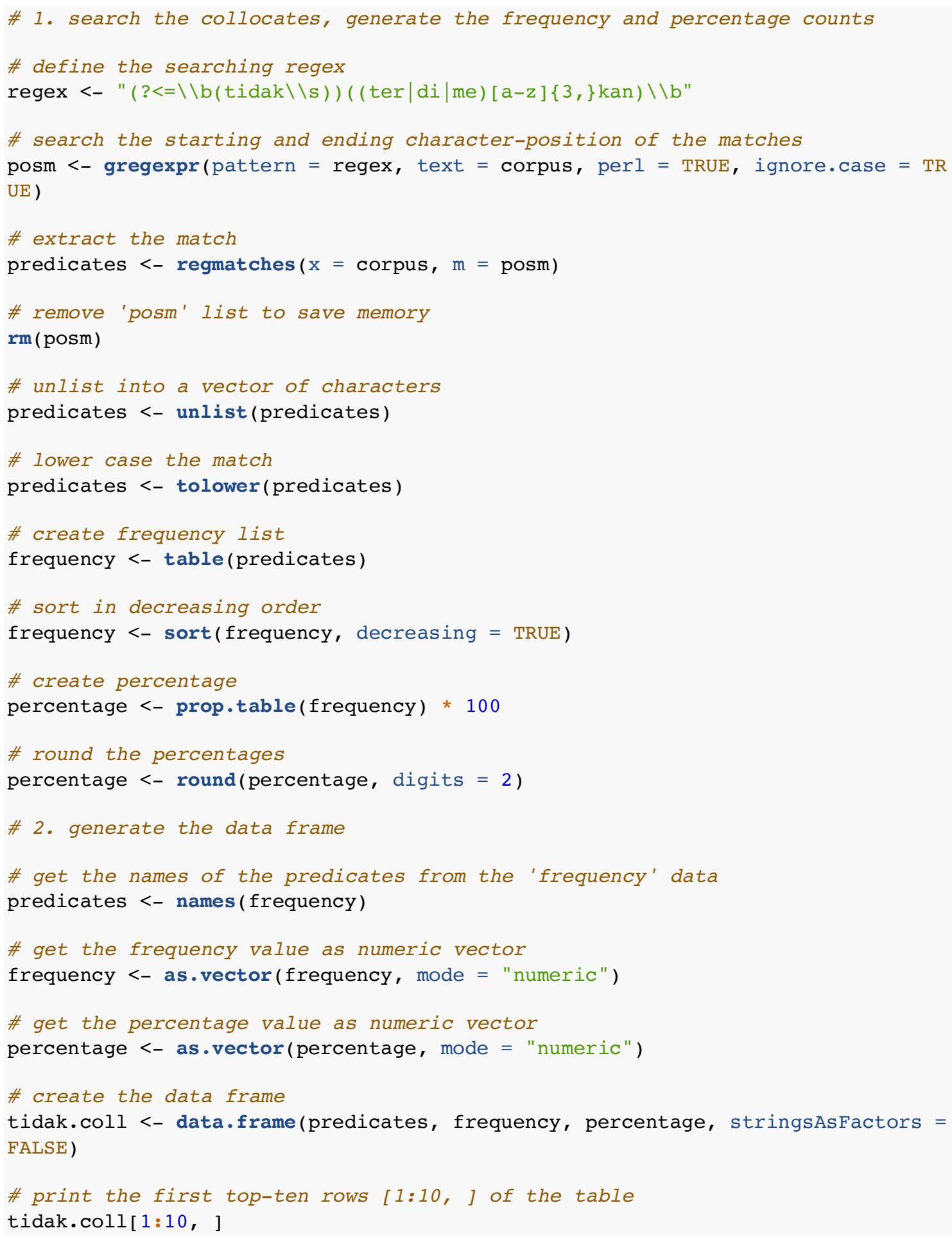


Table 2 Top-10 most frequent negated predicates with tidak

\begin{tabular}{lllrr} 
& predicates & gloss & frequency & percentage \\
\hline 1 & melakukan & to do & 669 & 6.11 \\
2 & memberikan & to give & 506 & 4.62 \\
3 & dilakukan & to be done & 314 & 2.87 \\
4 & menggunakan & to use & 299 & 2.73 \\
5 & mendapatkan & to receive; obtain & 286 & 2.61 \\
6 & menimbulkan & to cause to emerge & 271 & 2.48 \\
7 & ditemukan & to be found & 229 & 2.09 \\
8 & diinginkan & to be wanted & 226 & 2.06 \\
9 & menemukan & to find; discover & 183 & 1.67 \\
10 & menyebutkan & to mention & 158 & 1.44
\end{tabular}

For the reason of space, the codes for tak are not printed out in the paper. The codes are the same as tidak. One only needs to change (i) "tidak" with "tak" in the regex, and (ii) the name of the final data frame from tidak.coll to tak.coll. Table 3 shows the top-ten results for tak.

Table 3 Top-10 most frequent negated predicates with $t a k$

\begin{tabular}{lllrr} 
& predicates & gloss & frequency & percentage \\
\hline 1 & mengherankan & to (be) astound(ing) & 89 & 4.77 \\
2 & terkalahkan & (can) be defeated; defeatable & 87 & 4.67 \\
3 & terhindarkan & (can) be avoided; avoidable & 68 & 3.65 \\
4 & memberikan & to give & 51 & 2.74 \\
5 & diinginkan & to be wanted & 46 & 2.47 \\
6 & melakukan & to do & 44 & 2.36 \\
7 & terelakkan & (can) be avoided; avoidable & 44 & 2.36 \\
8 & diragukan & to be doubted & 43 & 2.31 \\
9 & menemukan & to find; discover & 41 & 2.20 \\
10 & menyurutkan & to lessen; abate & 41 & 2.20
\end{tabular}

There are at least two points that can be explored from the data of the negated-predicate collocates. First, we may investigate the total number of different types of verbs to be negated with tak and tidak. The different verbal types can further be measured, for instance, at the level of the number of the verbs conforming to the three constructional schemas mentioned above. The findings may elucidate the degree of association between the two negative forms and the three constructional schemas (cf., Section 4.3). The second analytical point is that we can rank all the negated collocates according to their statistical preferences/tendencies to be negated with tak in comparison to tidak; for this purpose, we will demonstrate the application of a quantitative corpus linguistic method called Distinctive Collexeme Analysis (cf., Section 4.4.1). The ranking may then show us which specific verbal predicates are relatively more distinctive to be negated with a given negation (cf., Section 4.4).

\subsection{Type frequencies of the negated-predicates and their schemas}

If we compare the number of rows in each data set (i.e., the tidak.coll and tak.coll data frames), tidak, in comparison to tak, has nearly three times more number of unique negated predicates conforming to the [me-X-kan], [di-X-kan], and [ter-X-kan] schemas. In our corpus, 
tidak negates 908 predicates; the total token frequency of the tidak-negated predicates is 10,945 . Meanwhile, tak negates 384 predicate types of the same constructional schemas; the total token frequency of the tak-negated predicates is 1,864 . The much higher type frequency of tidak (i.e., the number of unique negated predicates) suggests that tidak has wider applicability, which could also be triggered by its high frequency of occurrence in the corpus. To find the total number of the negated predicates, which is reflected by the total number of rows in each data frame, we can use nrow()with the data frame as the input argument, hence nrow(tak.coll) and nrow(tidak.coll). To get the total sum of token frequency of these predicates, we can use sum() with the frequency column as input argument; we access a column of a data frame in R using the dollar sign (\$), hence sum(tidak.coll\$frequency) and sum(tak.coll\$frequency).

The overall comparison above can be zoomed-in via determining, for each negation, the total number of the negated predicates (i.e., the type frequencies) conforming to the [me-X-kan], [di-X-kan], and [ter-X-kan] schemas. ${ }^{22}$ This question relates to the first analytical point mentioned at the end of Section 4.2 regarding the schema-specific association for tidak and tak. The answer to this question will be used to investigate the hypothesis proposed by Sneddon et al (2010, p. 203) regarding the nuances between tidak and tak in their usage tendency to negate certain type of predicate schemas, especially ter-prefix (see further below).

To find the schema-specific negated collocates, we search within the negated predicates column which predicates begins with each of the three prefixes, ensure that there are no overlapping predicate types for a given schema between tidak and tak, and count the total number of each set. For that purpose, firstly, we need to introduce another text-processing function in R called grep(). grep () searches for matches for each element in the input character vector. The output of grep () can be of two types: (i) numeric vector(s) indicating the position index of the match in the input character vectors (when the value argument of grep() is set to FALSE), or (ii) the match(es) itself as character vectors (when the value argument is set to TRUE). We briefly illustrate how grep () works below (see further Gries, 2009a, pp. 72-73).

When grep() is used without regex, it requires two main input-arguments: the search pattern specified in the pattern argument and the vector of character strings to be searched for in the $\mathrm{x}$ argument. Let us illustrate this below with a search-pattern input that is simply "di". We will search this pattern ("di") in the following six words as illustrations, two words for each of the three prefixes: mendirikan 'to establish sth.', mendiskusikan 'to discuss sth.' (for me-); terkalahkan 'defeatable; lit. be caused to be defeated', terhindarkan 'avoidable; lit be caused to be avoided' for (ter-); didirikan 'to be established', diterjemahkan 'to be translated' (for di-). The words are intentionally selected to illustrate (i) the output properties of grep() and (ii) the importance of specifying the search pattern with regex, especially when dealing with (Indonesian) morphological constructions. To be straightforward, we set the value argument to TRUE SO we can get the matches, rather than the position index of the matches.

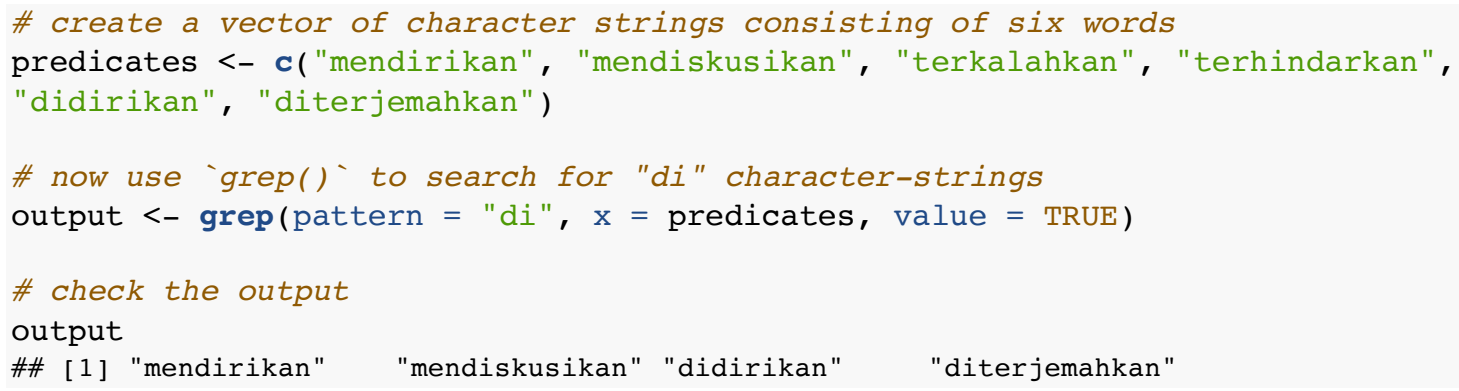


The output tells us something about what grep() does. First, feeding grep() with a certain input-pattern, such as "di", does not make R know that in fact the users, for instance, wish R to search for "di" where "di" only occurs at the beginning of the strings (as in diterjemahkan and didirikan), but not in the middle of the strings (as in mendirikan, mendiskusikan, and didirikan). This is the reason why four outputs/elements are returned by grep() for the search pattern "di", while we would expect, for our purpose, only two outputs, excluding the two me- prefixed words in which "di" does occur as part of them. Second, and it is quite related to the first one, grep() returns whether the search pattern occurs at all somewhere in the input character strings, but does not tell us the number of its occurrence; we can see in didirikan that the string "di" in fact occurs twice: didirikan.

Thus, to be more precise in our search pattern and let R "know" what a prefix (or a word) is, we need to design a regex by preceding the prefix with word boundary " $\backslash \backslash \mathrm{b}$ " that we have seen in Section 4.1, hence " $\backslash \backslash$ bdi" for searching $d i$ - prefixed words from the predicates vector. When using regex, the perl argument of grep( ) must be set to TRUE.

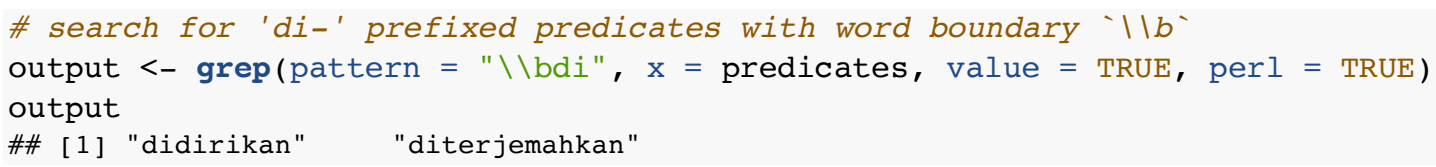

The output of grep () for a certain search pattern can be fed into length() to get the total number of matches found in the character vectors.

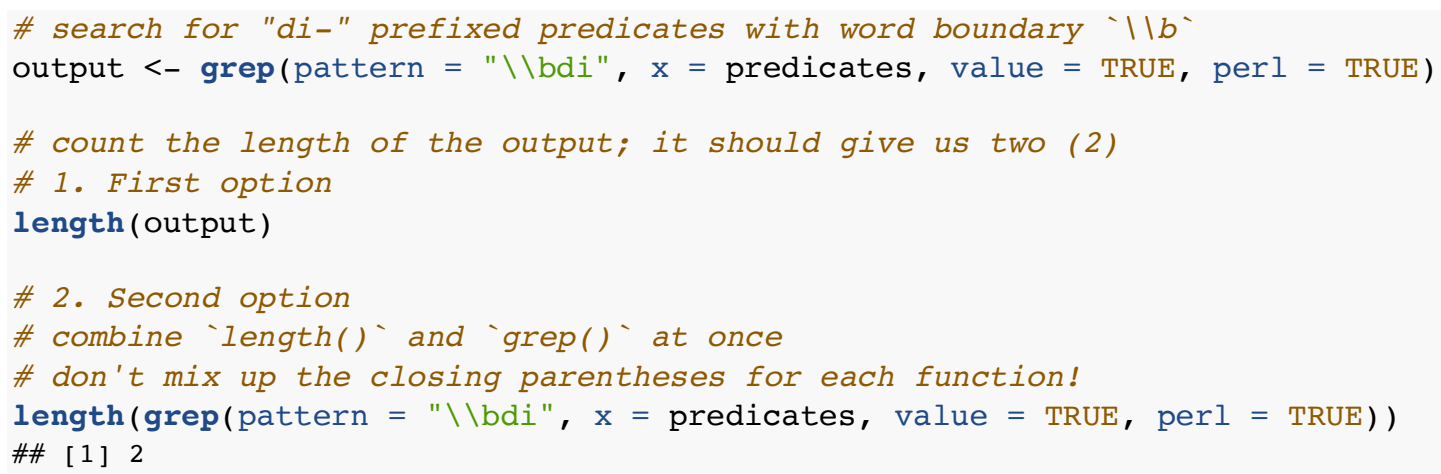

Now, we hope readers can imagine what should be done to answer our question regarding the total number of $m e-, d i$-, and ter-prefixed predicates negated with tidak and tak. The following two code-chunks present the procedures for each tidak and tak. The first one below shows how to get the character vector of all negated predicates from the columns of each negation data frame shown in Table 2 and Table 3 above.

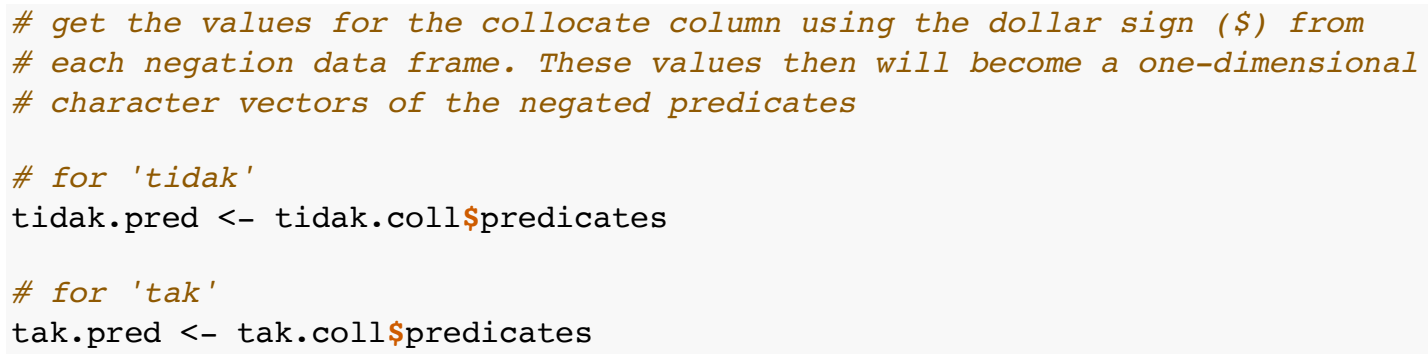

The next chunk shows the searching (with grep()) and counting (with length()) for the total number of certain morphological forms of the negated predicates. However, before we count the 
type frequency of certain form of the predicates, we exclude overlapping predicates between the two negations. That is, we count only unique predicates of certain form that are used with either tak or tidak, thus no one verb of a given morphological form appears more than once in this dataset (cf. Janda \& Lyashevskaya, 2013, pp. 217-218, 221, for similar approach). This procedure is performed to fulfil the independence assumption required by the chi-square test that we will use to determine the association of the schema of the predicates with the negations. For that purpose, we use setdiff() that requires two vector arguments ( $\mathrm{x}$ and $\mathrm{y}$ ); $\operatorname{setdiff}()$ determines which elements of $\mathrm{x}$ that are not found in $\mathrm{y}$, thus providing the unique item in $\mathrm{x}$.

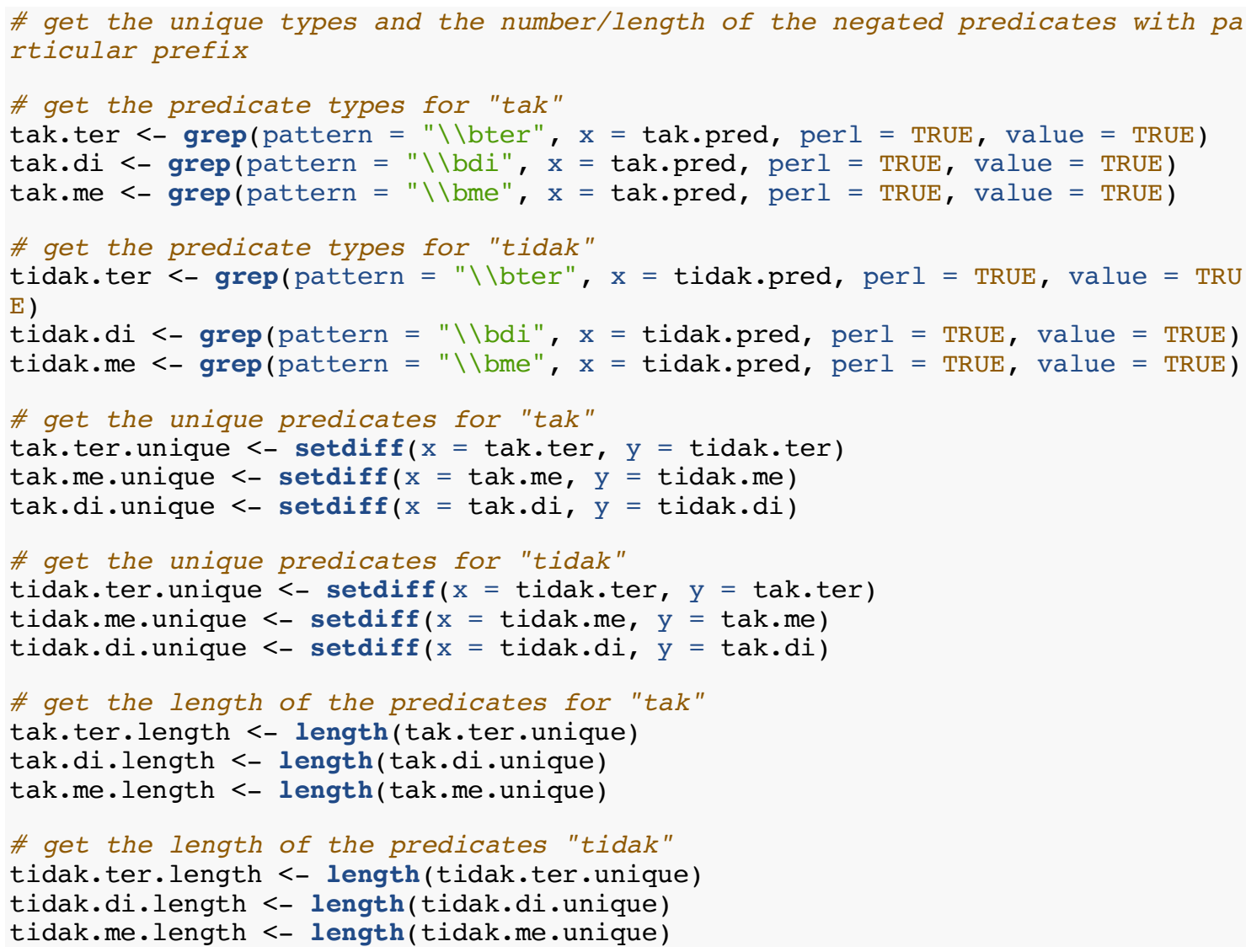

Next, we can inspect whether there are differences in the type frequencies for a given schema across tak and tidak. In order to determine this, we represent the data in the form of cross-tabulation/contingency table (Gries, 2009b, pp. 127-128) (cf., Table 4 below). The following code-chunk shows how to create a contingency table from the numeric vectors indicating the number of prefix types of the negated predicates.

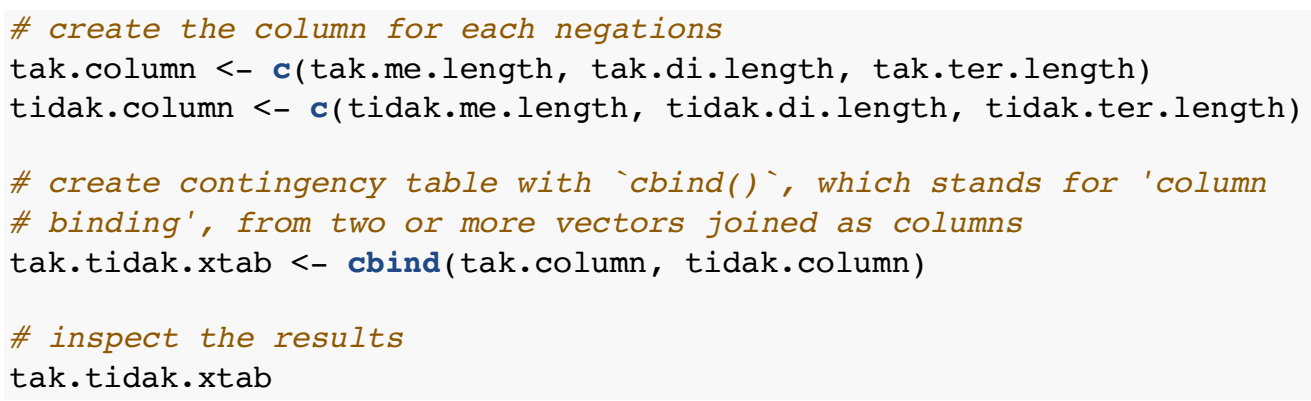




$\begin{array}{lrrr}\text { \#\# } & & \text { tak.column } & \text { tidak.column } \\ \text { \#\# }[1,] & 29 & 327 \\ \text { \#\# }[2,] & 21 & 246 \\ \text { \#\# }[3,] & 20 & 21\end{array}$

The first $([1]$,$) , second ([2]$,$) , and third ([3]$,$) rows indicate, respectively, the predicates with$ $m e-$, di-, and ter-. We can re-label the columns and provide names for the rows with the following codes.

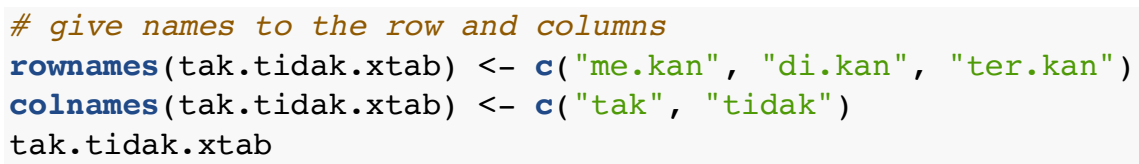

Table 4 Type frequencies of the three negated-predicate schemas between tak and tidak.

\begin{tabular}{lrr} 
& tak & tidak \\
\hline me.kan & 29 & 327 \\
di.kan & 21 & 246 \\
ter.kan & 20 & 21
\end{tabular}

The data in Table 4 indicates that predicates with [ter-X-kan] schema are the least type negated by both tidak and tak. Meanwhile predicates with [me-X-kan] schema is the most common across the two negations. The following chunk shows how to generate table of proportion/relative frequencies with prop.table() that we have used in Section 4.1.

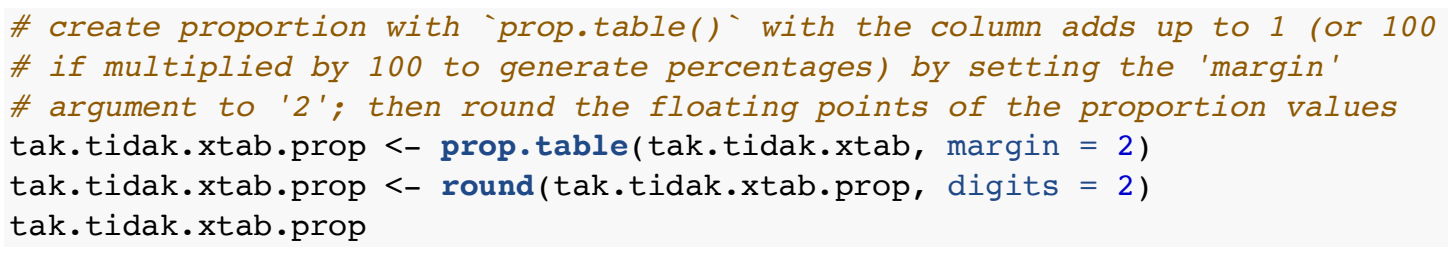

Table 5 Relative type-frequencies of the three negated-predicate schemas between tak and tidak

\begin{tabular}{lrr} 
& tak & tidak \\
\hline me.kan & 0.41 & 0.55 \\
di.kan & 0.30 & 0.41 \\
ter.kan & 0.29 & 0.04
\end{tabular}

A slightly different picture emerges when considering the proportions/relative typefrequencies shown in Table 5. The form tak has relatively more types of [ter-X-kan] predicates to be negated (i.e., $29 \%$ types) as compared to tidak (i.e., $4 \%$ types), even though in the raw type-frequency in Table 4 tidak has more number of [ter-X-kan] predicates than tak by just one type. Figure 4 below clearly shows the association of tak with [ter-X-kan] schemas. This kind of plot is called a mosaic plot (Gries, 2009b, pp. 129-130, 168; Levshina, 2015, p. 219). We can use mosaicplot () from the base $\mathrm{R}$ with the cross-tabulation table as the key input-argument.

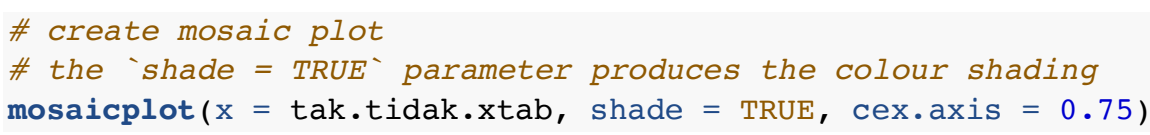




\section{tak.tidak.xtab}

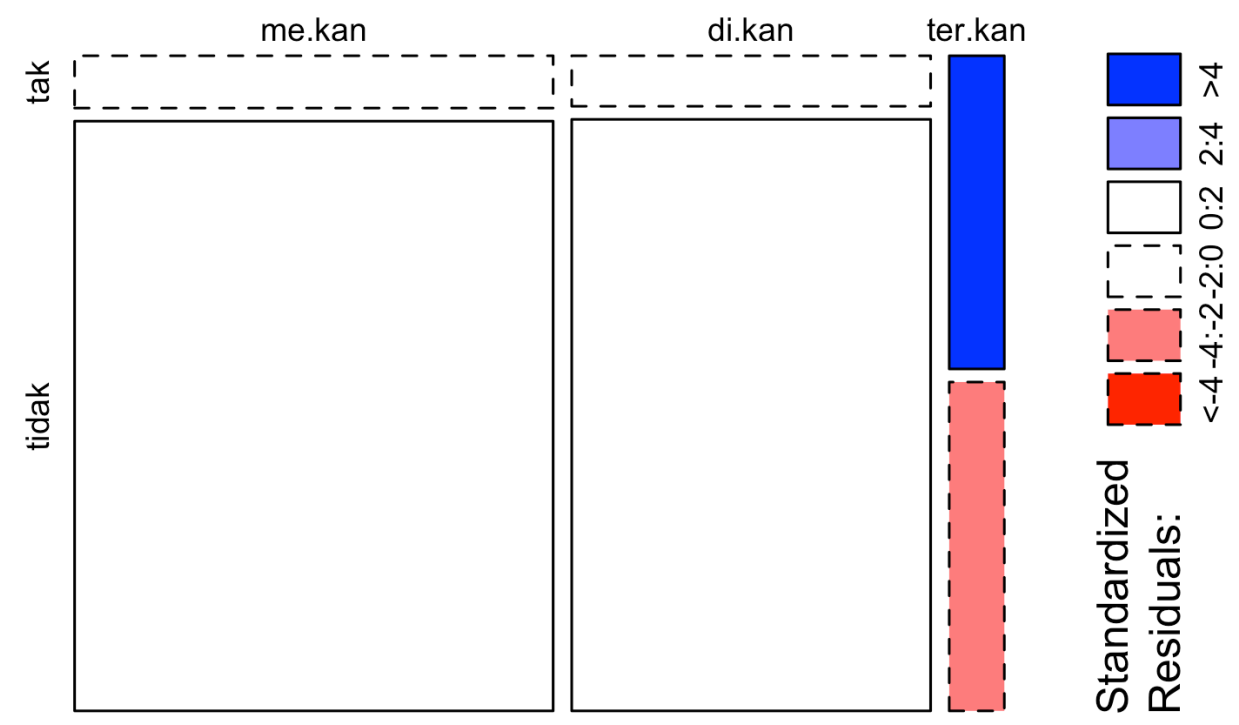

Figure 4 Mosaic plot for the type frequencies of the negated-predicate schemas with tak and tidak

The area inside the plot reflect the total proportion of the cell-values, rows, and columns in the contingency table. For instance, the bar for [me-X-kan] is the widest since, overall, this schema has the highest number of predicate types to be negated by the two negations, while [ter-X-kan] schema has the lowest predicate types. Then, the row-area occupied by tidak, especially in the [me-X-kan] and [di-X-kan] schemas, are wider than for the [ter-X-kan] schema, because tidak has more number of predicates for these two schemas compared to tak.

The dashed boxes in Figure 4 indicates the values of SCHEMAS NEGATIONS combination whose type frequencies are less frequent than expected under the null-assumption that each negation should have equal ratio of negated predicates conforming to the three schemas. That is, a null-assumption asserts that there is no association between negation forms and the three negated-predicate schemas, in the sense that no difference exists in the ratio of predicates of a given schema to be negated by the two negations (cf., Gries, 2009b, pp. 168171, for details regarding observed vs. expected frequencies) (see also Section 4.4.1 below). The clear effect is shown by the higher-than-expected type frequency for the [ter-X-kan] schema to be negated by tak compared to tidak. It is indicated by the solid-line rectangle with violet-blue shading, showing positive standardised residuals (see also Table 7 below). In short, the effect suggests that in our database, tak, in comparison to tidak, prefers to negate verbal predicates with [ter-X-kan] schema than the other two schemas.

An alternative to the mosaic plot for visualising association between two categorical variables, such as NEGATION and SCHEMAS, is an association plot. See the code-chunk below.

\# association plot with the contingency table input

assocplot $(\mathrm{x}=$ tak.tidak.xtab, $\mathrm{col}=\mathbf{c}($ "black", "grey90")) 


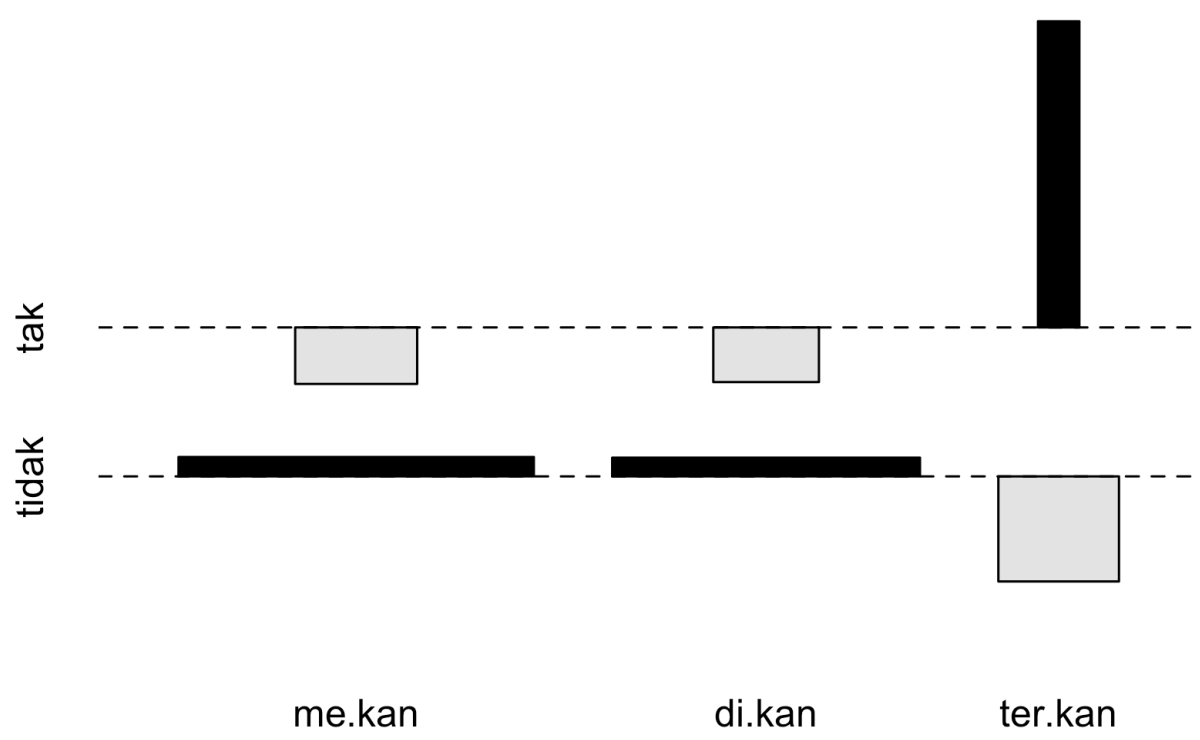

Figure 5 Association plot between the negated-predicate schemas and the negation forms

The black rectangle(s) growing from the dashed line indicates predicate schema(s) (x-axis) whose type frequency is overrepresented than expected by chance for a given negation form $(y$ axis). The falling grey rectangle(s) represents the underrepresented combination(s). It is clearly shown that the combination of tak and [ter-X-kan] schema types are more frequent than expected as of tidak with [di-X-kan] schema.

We can further test whether such differences in type frequency of certain negatedpredicate schemas for tak and tidak are due to chance. For this purpose, we use significance testing for contingency table, such as chi-square test (Gries, 2013c, pp. 178-189; cf., Janda, 2013, pp. 9-14; Levshina, 2015, p. 210). The chi-square test requires that $80 \%$ of the expected frequencies are $\geq 5$ and all expected frequencies are $>1$ (Gries, 2013c, p. 179). To determine the expected frequency for each cell in Table 4, we feed the table into the chisq.test () function and retrieve the expected elements of the results. The output is shown in Table 6 .

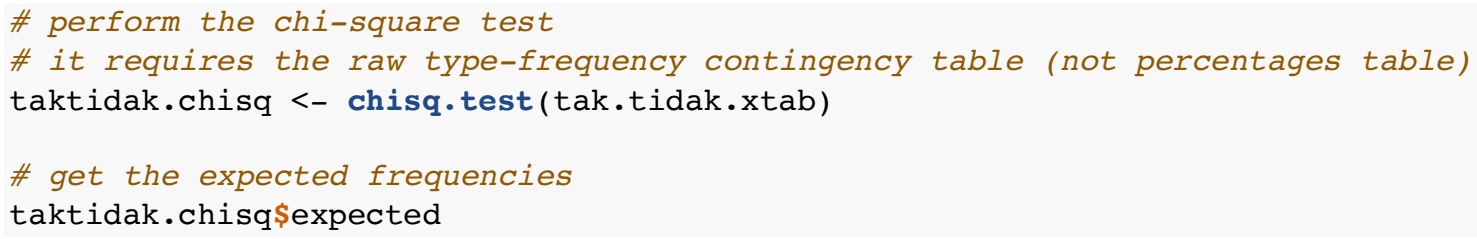

Table 6 Expected frequencies for the contingency table.

\begin{tabular}{lrr} 
& tak & tidak \\
\hline me.kan & 37.530121 & 318.46988 \\
di.kan & 28.147590 & 238.85241 \\
ter.kan & 4.322289 & 36.67771
\end{tabular}

Table 6 shows that 5 of the total 6 cells (or $83.33 \%$ of the cells) contain expected frequencies larger than five, and all of the expected frequencies are larger than one (Gries, 2013c, p. 179). In that case, the results of the chi-square test for the data can be reported.

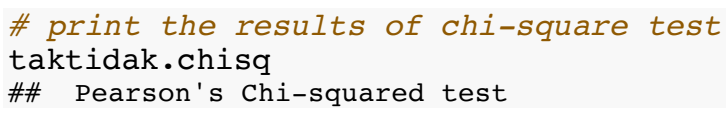


\#\#

\#\# data: tak.tidak.xtab

\#\# $\mathrm{x}$-squared $=67.763, \mathrm{df}=2, \mathrm{p}$-value $=1.929 \mathrm{e}-15$

The $p$-value ${ }^{23}$ of the chi-square test, which is below the conventional significance level of 0.05 , suggests that there is a highly significant association between the constructional schemas of the negated predicates and the two negation forms ${ }^{24}$. The mosaic plot (cf., Figure 4) and the association plot (cf., Figure 5) give us visual representations for the direction of the association, namely which negation (dis)prefers which constructional schemas on the basis of the deviation of the observed frequencies from the expected frequencies for each crosstabulation cell. The direction of the association is also reflected in the values of the so-called standardised residuals of a contingency table (cf. Table 7 below), the visualisation of which has been shown in Figure 4. This residual represents which cell has frequency value that significantly deviates from the expected frequency (Levshina, 2015, p. 210). Standardised residuals can be retrieved from the results of a chi-square test as follows.

\# get the standardised residuals

taktidak.chisq\$stdres

Table 7 Standardised residuals for the contingency table.

\begin{tabular}{lrr} 
& tak & tidak \\
\hline me.kan & -2.161547 & 2.161547 \\
di.kan & -1.842123 & 1.842123 \\
ter.kan & 8.231075 & -8.231075
\end{tabular}

Cells with standardised residuals greater than 1.96 or smaller than -1.96 makes significant contribution to the chi-square $/ X^{2}$ value at the significance level of 0.05 . The values of 2.58 or -2.58 represent residuals for the significance level of 0.01 (Levshina, 2015, p. 221). The positive standardised residuals indicate positive deviation, that is cell-values that are more frequent than expected. The negative residuals are the opposite. Table 7 shows that cells for [ter-X-kan] schema with tak and tidak contribute most to the significant association at the significance level of below 0.01 , with the combination of tak and [ter-X-kan] schema exhibits positive deviation from the expected frequency.

How can we relate this finding to what Indonesian grammar textbook hypothesises regarding the use of the two negating forms? Sneddon et al (2010, p. 203) states that tak "was once obligatory before ter- verbs", even though "in modern Indonesian tidak is also common in this position" (i.e., in the position of negating ter- verbs in general). Our quantitative corpusbased analysis with the chi-square test offers a slightly different nuance. Namely, tak negation is not only obligatory before ter- verb once in the past, but it does maintain its typical usages with this type of verbs in modern Indonesian, at least as framed in the [NEGATION + PREDICATES] schema. Meanwhile tidak shows significant dissociation for this type of verbs. Indeed, our result is limited by the corpus for this study, collocational pattern schema (i.e., the [NEGATION + PREDICATES] schema), the regex design, and more importantly by the very specific ter- verb schema we focused on (i.e., [ter-X-kan] schema).

Despite the non-random/significant association between predicates with [ter-X-kan] schema and tak negation, the magnitude/size of this effect is moderate (Cramer's $V=0.319$ ) (cf., Gries, 2009b, pp. 173-174; Janda, 2013, pp. 10-11; Levshina, 2015, pp. 208-210) ) $^{25}$ To sum up, we found that tak has preference to negate predicates with [ter-X-kan] schema in opposition of the schema's dissociation with tidak (cf., Figure 5). A chi-square test for 
independence indicates that this association cannot be due to chance $\left(X^{2}=67.76 ; d f=2 ; p_{\text {two-tailed }}\right.$ $<0.001)$; however, this effect is moderate based on the Cramer's $V$ value.

\subsection{The verb-specific preferences of tak and tidak}

This final analytical section demonstrates that tak and tidak exhibit verb-specific preferences in their use to negate predicates. Relative preferences for a given negation to negate a set of certain predicates can be another benchmark in distinguishing the use of alternating variant such as tidak and tak (cf., Gries \& Stefanowitsch, 2004; Hilpert, 2006). We argue that such collocational preferences provide a more fine-grained level in characterising the use of tidak and tak. We will illustrate this idea by performing Distinctive Collexeme Analysis on the basis of the whole token frequency of the negated-predicate collocates of tak and tidak that we have retrieved in Section 4.2 and stored in the form of data frames (i.e., tidak.coll and tak.coll). The snippets of these collocational data have been presented in Table 2 and Table 3 in Section 4.2.

\subsubsection{Distinctive Collexeme Analysis: An overview}

The method of Distinctive Collexeme Analysis (DCA) (cf., Gries \& Stefanowitsch, 2004) is a member of a family of quantitative methods called the Collostructional Analysis (CA) (cf., Gries, 2012, 2013b; Hilpert, 2014; Stefanowitsch, 2013, 2014; Stefanowitsch \& Gries, 2003, 2009 , inter alia). DCA can be used to reveal differences between two (semantically or functionally) related constructions in terms of statistical association for words that can occur in a slot in the constructions (Stefanowitsch, 2014, p. 226). Among the previous applications of DCA include contrasting verbs that are distinctive for passive vs. active construction in English, preferred infinitival collocates of will vs. be going to, and verbs strongly attracted to ditransitive vs. prepositional dative constructions (cf., Gries \& Stefanowitsch, 2004), or contrasting the English hedges, namely sort of vs. kind of (Gries \& David, 2007).

In our case study, the constructions are negations with a slot for the predicates negated with tidak and tak. In CA, lexemes (e.g., predicates) occurring in a particular slot (e.g., the negated predicates slot) in a construction (e.g., the Negating Construction) are referred to as the collexemes of the construction. With DCA, we aim to uncover whether there are negated collexemes that have significant statistical association with the negated-predicate slot for one of the two Negating Constructions. In other words, we aim to determine whether tidak and tak exhibit verb-specific preferences that best distinguish between these two (seemingly alternating) negations in their usage to negate predicates. In part, the finding may show us when writers (of online news genre in this case) tend to choose tak over tidak to negate certain type of verbal predicates (cf., Hilpert, 2014, p. 398). Table 8 presents a schematic cross-tabulation design required as input for performing DCA.

Table 8 Co-occurrence frequencies required for measuring the distinctiveness/statistical association of a collexeme $X$ in two near-synonymous constructions

\begin{tabular}{lll} 
& Construction_A & Construction_B \\
\hline collexeme $X$ & $a$ & $b$ \\
collexeme $A L L-O T H E R S$ & $c$ & $d$
\end{tabular}

Cell $a$ and $b$ in Table 8 represent co-occurrence frequencies of a given negated collexeme (i.e., the collexeme $X$ ) with Construction_A and Construction_B respectively (cf., 
Levshina, 2015, p. 244, Table 11.1). Cell $c$ and $d$ represents the remaining token frequencies of the other negated collexemes occurring with Construction_A and Construction_B. These crosstabulation data can be evaluated with distributional statistics for statistical significance. CA, including DCA, uses the one-tailed Fisher Yates Exact (FYE) test for that purpose (cf., Gries, 2013b, p. 1381). In the remainder of this section, we discuss this underlying statistical technique in more details. As an example, we will determine whether, and to what extent, terkalahkan '(can) be defeated; defeatable' is a distinctive negated-collexeme of one of the two negations, namely tidak (Construction_A) and tak (Construction_B). Table 9 below shows the input frequency-data for the computation of FYE.

Table 9 Co-occurrence frequency of terkalahkan negated with tidak and tak

\begin{tabular}{llll} 
& tidak & tak & Row totals \\
\hline terkalahkan & 47 (exp: 114.5) & 87 (exp: 19.5) & 134 \\
others & $10,898($ exp: 10,830.5) & 1,777 (exp: 1,844.5) & 12,675 \\
Column totals & 10,945 & 1,864 & 12,809
\end{tabular}

For expository reasons, the observed co-occurrence frequencies for terkalahkan with the two Negating Constructions are followed by their corresponding expected frequencies shown in parentheses. The expected frequency of a given co-occurrence represents the frequency that one would expect under the null-hypothesis that the proportion of a collexeme was equally distributed across the two constructions under study (cf., Levshina, 2015, pp. 210-211) (see also Section 4.3 above). In our case, under the null, there should be no difference in the cooccurrence token frequencies of a given predicate, such as terkalahkan, to be negated with tak and tidak.

The expected frequency of tidak with terkalahkan is computed by multiplying the total frequency of tidak (i.e., 10,945) with the total frequency of terkalahkan (i.e., 134) and then dividing the multiplication result with the total tokens in the sample (i.e., 12,809), which is the sum of the margin in Table 9 . Hence, $(10,945 * 134) / 12,809=114.5$. The expected frequency for tak with terkalahkan is calculated similarly; the only difference is the total frequency of terkalahkan is now multiplied with the total frequency of tak (i.e., 1,864) and then dividied with the total tokens in the sample. Hence, $(1,864 * 134) / 12,809=19.5$ (cf., Gries, 2013b, p. 1381).

We can submit the data in Table 9 to an FYE test; in R, we can use the fisher.test() function $^{26}$. The function requires a 2-by-2 cross-tabulation input of each observed co-occurrence frequencies of a collexeme with the constructions (as in Table 9). When using the fisher.test(), a one-tailed FYE test can be performed by setting its alternative argument to (i) "greater" when the observed frequency of the cell of interest (i.e., $a$ ) is greater than the expected frequency, or to (ii) "less" when the observed frequency is less than the expected frequency. ${ }^{27}$ Under the null-assumption that the co-occurrence frequency of the collexeme across the two constructions should be equal, the FYE test computes the chance probability of finding a given observed frequency, or even more extreme, given the total frequency of the collexeme under consideration (cf., Janda, 2013, pp. 14-15). Small $p_{\mathrm{FYE}}$-value suggests a low likelihood that the observed frequencies of a collexeme with the two constructions, and its deviation even more, would occur due to chance. If we submit the frequency data in Table 9 into fisher.test() and set the alternative argument to "less" because the co-occurrence frequency of the collexeme with the reference construction ${ }^{28}$ (i.e., Construction A) is less frequent than expected, the FYE outputs a very small $p$-value: $8.753 \mathrm{e}-41$ (cf., code-chunk below). 


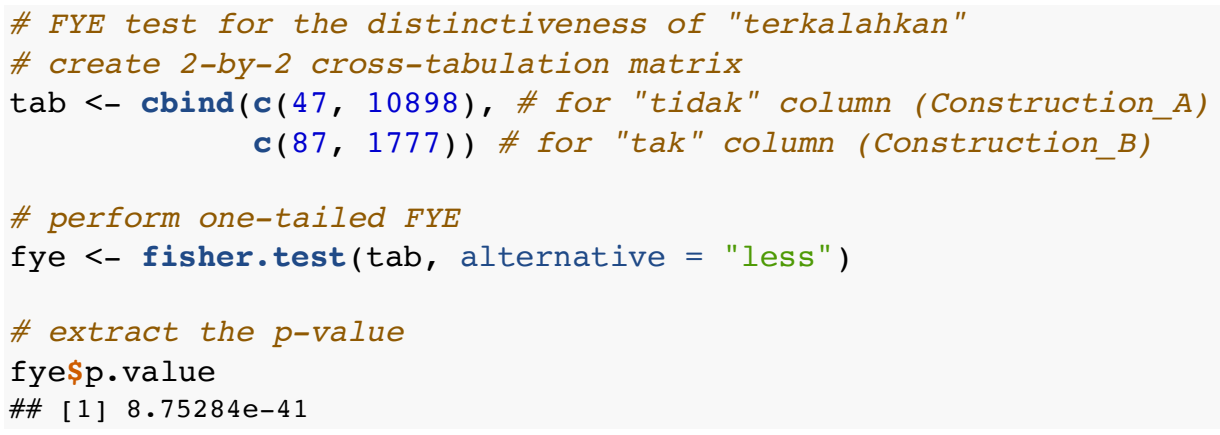

This small $p$-value indicates that terkalahkan is highly significantly distinctive for one of the two negations but does not tell us for which one.

The distinctiveness of a collexeme for one of the pair of constructions can be determined from the direction in which the observed co-occurrence frequencies of the collexeme with the two constructions deviate from their expected frequencies. If an observed frequency significantly deviates in a positive direction (i.e., occurring more frequently) than its expected frequency, it represents a positive association, or attraction, between the collexemes and one of the two constructions; the reverse is an observed frequency occurring less frequently than expected, the situation showing a negative association, or repulsion, between the collexeme and one of the two constructions (Gries \& Stefanowitsch, 2004, p. 103). In DCA, if a collexeme shows attraction for one construction, the given collexeme will be automatically repelled by the other construction (Stefanowitsch, 2005, p. 194, note no. 8); essentially, thus, there are no repelled collexemes in DCA because each collexeme will be assigned into one or the other constructions (Stefanowitsch \& Gries, 2009, p. 946).

Table 9 shows that terkalahkan co-occurs over four time as often than expected with tak and over twice less often than expected with tidak. Such deviation, and its statistical significance, indicates that terkalahkan is significantly distinctive for tak, but significantly not for tidak. In a way, this shows us an association between the collexeme and the construction, indicating that the collexeme is a distinctive collexeme of the given construction in comparison to the other construction.

In CA, the $p_{\mathrm{FYE}}$-value are $\log _{10}$-transformed into the association strength values called Coll(ostruction) Str(ength) (henceforth, CollStr) (Gries, Hampe, \& Schönefeld, 2005). This transformation will give positive CollStr values showing attraction/association and negative CollStr values indicating repulsion/dissociation. The commonly used threshold in indicating significant collostruction strength is "CollStr $>1.30103$ ", which is equal to $p_{\mathrm{FYE}}<0.05$. Higher cut-off points can also be set, i.e., "CollStr $>2$ ", equal to $p_{\mathrm{FYE}}<0.01$, and "CollStr $>3$ ", equal to $p_{\mathrm{FYE}}<0.001$. These cut-off points are also applicable to indicate significant repulsion when the CollStr values are negative. The higher the CollStr values, the stronger the distinctiveness of a collexeme with a construction, and vice versa.

If we repeat this procedure for all the negated collexemes, eventually, DCA allows us to highlight which set of negated collexemes are distinctive for each negation. One could of course repeat manually the FYE test in the code-chunk above in $\mathrm{R}$ for all the co-occurrence frequencies of the identified negated-predicate collexemes. However, it would be more effective and elegant to wrap this procedure into a programming function that we will turn to in Section 4.4.3 below. 


\subsubsection{Preparing input data for Distinctive Collexeme Analysis}

Before performing the Distinctive Collexeme Analysis (DCA) for the two negations using the dist.coll() $\mathrm{R}$ function that we designed (cf., Section 4.4.3), we need to do a bit of data wrangling with the two collocational tables of tak (i.e., tak.coll data frame) and tidak (tidak.coll) that we have generated in Section 4.2. It is because we designed the function for a designated input data so that the function can run. The required input-table must consist of three columns (cf., Table 10 below): the first column containing the negated-predicate collexemes and the other two subsequent columns contain the co-occurrence frequencies of the collexemes with tidak (i.e., Construction $\mathrm{A}$ in the second column) and tak (i.e., Construction B in the third column) (cf., Hilpert, 2014, p. 399; Levshina, 2015, pp. 244-245).

Given our tak.coll and tidak.coll data frames, the first step is to leave out the percentage column and to select only the first two columns, namely (i) the predicates containing the negated predicates for each negation and (ii) the frequency containing the cooccurrence token frequency of each predicate with tidak and tak. The second step is renaming the second column (i.e., frequency) for each table with the corresponding construction labels (i.e., "tak" and "tidak"). Having one common label (i.e., predicates) for one of the two columns, and specifying a unique column label corresponding to the two negations for each of the frequency column, allow the merging of the two tables into a single input-table required by our DCA function (i.e., the third step, cf., below). The following code-chunk shows how to perform the first two procedures (selecting columns and renaming a column) for tidak.

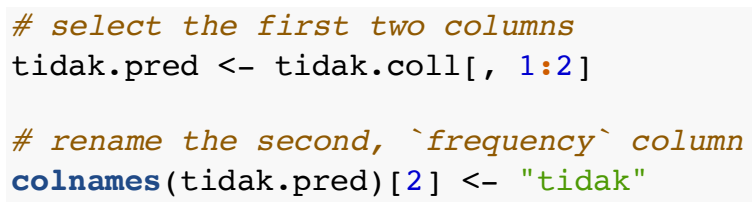

The chunk below does the same thing as before, now for tak data.

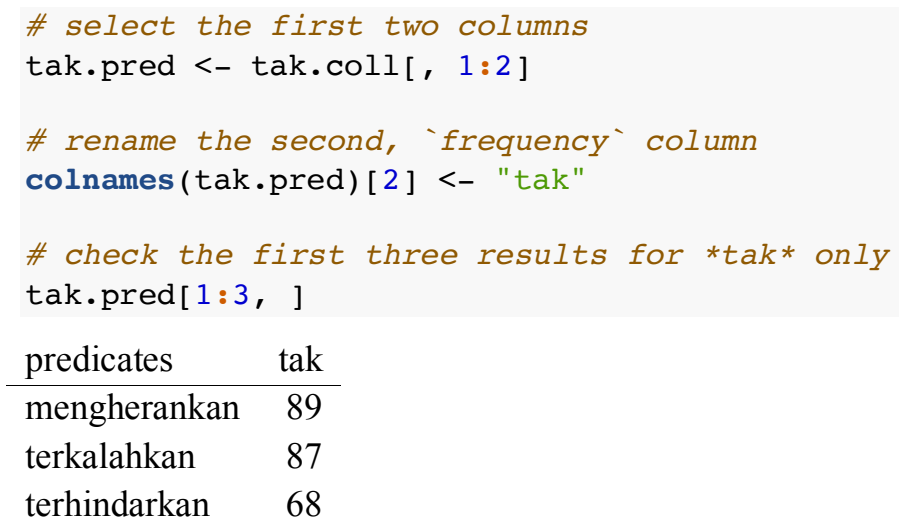

The third step is to merge the above two tables of tidak.pred and tak.pred into a single table using merge() (cf., the code-chunk below). The $\mathrm{x}$ argument of merge() is supplied with the first data frame and the $\mathrm{y}$ argument is supplied with the second one. We merged tidak.pred and tak.pred via matching the predicates column in each table specified in the by argument of merge (). We then check the first six rows of the merged table with head( ).

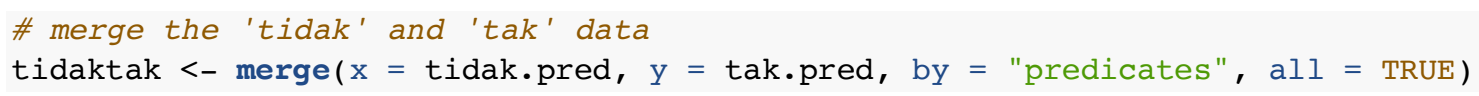




$\begin{aligned} & \text { \# head(tidaktak) } \\
& \text { head(tidaktak) }\end{aligned}$
\begin{tabular}{lrr} 
predicates & tidak & tak \\
\hline diabaikan & 5 & 1 \\
diacuhkan & 3 & NA \\
diadakan & 1 & NA \\
diagendakan & 2 & NA \\
diajarkan & 7 & 1 \\
diajukan & 3 & NA
\end{tabular}

The NA values in one of the frequency columns indicate that the given predicates are not found (even once) in the corpus used to be negated with one of the two negations in [tidak/tak + PREDICATES] schema. For DCA to run, these NA values have to be replaced with zero (0). The following code shows how to do that in R. The idea of the code is (i) to subset, with square brackets, all NA elements of the tidaktak table (hence, the tidaktak [is.na(tidaktak)] functioncall) and (ii) to replace them with zero (cf., Levshina, 2015, pp. 244-245).

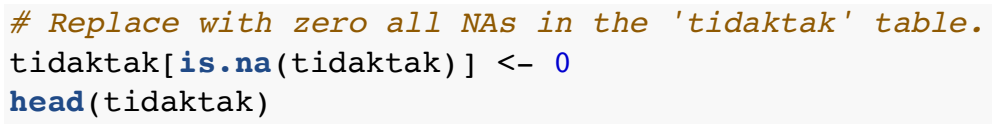

Table 10 Co-occurrence frequency of tidak and tak with the negated predicates

\begin{tabular}{lrr} 
predicates & tidak & tak \\
\hline diabaikan & 5 & 1 \\
diacuhkan & 3 & 0 \\
diadakan & 1 & 0 \\
diagendakan & 2 & 0 \\
diajarkan & 7 & 1 \\
diajukan & 3 & 0
\end{tabular}

\subsubsection{Performing DCA with the dist.coll() function}

To perform DCA with in-console output in $\mathrm{R}$, we have designed a function called dist.coll().${ }^{29}$ The function requires three arguments. The first and most important one is the $\mathrm{df}$ argument, standing for "data frame". The input data frame should contain three columns following the format of the tidaktak data frame in Table 10. The first column is the (predicate) collexemes/collocates of the construction. The second and third columns are frequencies of the collexemes with each of the two constructions that do not contain the NA values (cf., Section 4.4.2). The second argument is one.tailed, which specifies whether to perform one-tailed FYE test (i.e., TRUE, the default) or two-tailed (thus, set to FALSE). The third argument is collstr.float.digit, specifying the floating digits for the Collostruction Strength.

We also designed two other functions to retrieve the top-20 most distinctive collexemes for each of the two constructions: dist.for.A() and dist.for.B(). For these functions, the first and most important argument is dca.out, which is the output table of dist.coll(); the second argument, that is top. $\mathrm{n}($ ), is set by default to 20 , which can be modified by users. The following chunk illustrates the use of dist.coll() for performing one-tailed FYE in DCA with our tidaktak data. 


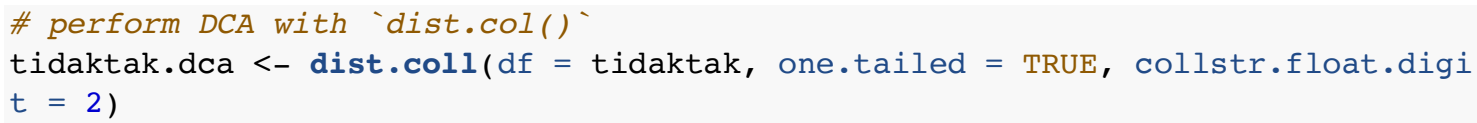

To retrieve the most distinctive negated collexemes for tak, which is the construction $\mathrm{B}$ in the input-table for dist.coll (), use the dist.for.B() function as shown below ${ }^{30}$ (cf., Table 11).

\# retrieve the top-20 most distinctive negated-collexems for 'tak' dist.for.B(dca.out $=$ tidaktak.dca, top. $n=20)$

Table 11 Top-20 distinctive negated collexemes for tak

\begin{tabular}{|c|c|c|c|c|c|c|c|}
\hline & predicates & gloss & tidak & tak & assoc & p.fye & collstr \\
\hline 1 & terkalahkan & (can) be defeated; defeatable & 47 & 87 & $\mathrm{~A}<\mathrm{B}$ & $8.75 \mathrm{e}-41$ & 40.06 \\
\hline 2 & terhindarkan & (can) be avoided; avoidable & 20 & 68 & $\mathrm{~A}<\mathrm{B}$ & $6.42 \mathrm{e}-40$ & 39.19 \\
\hline 3 & mengherankan & to (be) astound(ing) & 103 & 89 & $\mathrm{~A}<\mathrm{B}$ & $2.40 \mathrm{e}-26$ & 25.62 \\
\hline 4 & terelakkan & (can) be avoided; avoidable & 19 & 44 & $\mathrm{~A}<\mathrm{B}$ & $3.37 e-23$ & 22.47 \\
\hline 5 & terpisahkan & (can) be separated; separatable & 23 & 38 & $\mathrm{~A}<\mathrm{B}$ & $1.34 \mathrm{e}-17$ & 16.87 \\
\hline 6 & terlupakan & (can) be forgotten; forgettable & 9 & 29 & $\mathrm{~A}<\mathrm{B}$ & $1.87 \mathrm{e}-17$ & 16.73 \\
\hline 7 & terbantahkan & (can) be disputed; disputable & 12 & 30 & $\mathrm{~A}<\mathrm{B}$ & $1.16 \mathrm{e}-16$ & 15.93 \\
\hline 8 & tergantikan & (can) be $r$ & 1 & 20 & $\mathrm{~A}<\mathrm{B}$ & $3.01 \mathrm{e}-16$ & 15.52 \\
\hline 9 & menyurutkan & to lessen; & 59 & 41 & $\mathrm{~A}<\mathrm{B}$ & $9.48 \mathrm{e}-11$ & 10.02 \\
\hline 10 & terselamatkan & (can) & 2 & 11 & $\mathrm{~A}<\mathrm{B}$ & $3.55 \mathrm{e}-08$ & 7.45 \\
\hline 11 & membuahkan & to produ & 44 & 30 & $\mathrm{~A}<\mathrm{B}$ & $4.19 \mathrm{e}-08$ & 7.38 \\
\hline 12 & tertahankan & (can) be $\mathrm{h}$ & 9 & 14 & $\mathrm{~A}<\mathrm{B}$ & $4.08 \mathrm{e}-07$ & 6.39 \\
\hline 13 & diragukan & oubted & 100 & 43 & $\mathrm{~A}<\mathrm{B}$ & $1.42 \mathrm{e}-06$ & 5.85 \\
\hline 14 & mengenakkan & cause to be & 20 & 17 & $\mathrm{~A}<\mathrm{B}$ & $4.75 \mathrm{e}-06$ & 5.32 \\
\hline 15 & terbayangkan & (can) be imagined; imaginable & 12 & 13 & $\mathrm{~A}<\mathrm{B}$ & $1.18 \mathrm{e}-05$ & 4.93 \\
\hline 16 & terelakan & (can) be let go & 1 & 6 & $\mathrm{~A}<\mathrm{B}$ & $5.78 \mathrm{e}-05$ & 4.24 \\
\hline 17 & terperikan & (can) be expressed; expressible & 0 & 5 & $\mathrm{~A}<\mathrm{B}$ & $6.50 \mathrm{e}-05$ & 4.19 \\
\hline 18 & mematahkan & to break & 1 & 4 & $\mathrm{~A}<\mathrm{B}$ & $1.98 \mathrm{e}-03$ & 2.70 \\
\hline 19 & termaafkan & (can) be $f$ & 1 & 4 & $\mathrm{~A}<\mathrm{B}$ & $1.98 \mathrm{e}-03$ & 2.70 \\
\hline 20 & tergoyahkan & (can) be shaken & 10 & 8 & $\mathrm{~A}<\mathrm{B}$ & $2.21 \mathrm{e}-03$ & 2.65 \\
\hline
\end{tabular}

The assoc column with the value "A $<$ B" indicates that the observed co-occurrence frequency of a given predicate is more frequent than expected with tak (i.e., "B"), but less frequent with tidak (i.e., "A"). The collstr column shows the CollStr values derived from the negative $\log _{10^{-}}$

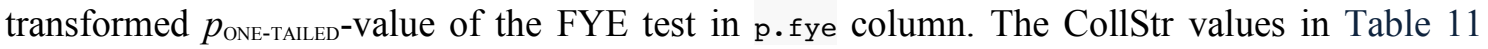
show the magnitude of distinctiveness of the predicates with tak. In relation to tidak, these CollStr values can also be interpreted as the degree of repulsion, or indistinctiveness, of the predicates with tidak (cf., Section 4.4.1 for interpreting results of DCA). Moreover, the CollStr values for tak, at least in the first eight rows, are (much) higher than the CollStr for the top collexemes for tidak (cf., Table 12 for tidak below). This indicates much stronger distinctiveness of these predicates with the given construction (i.e., tak).

As can further be seen from Table $11,70 \%$ of the top- 20 most distinctive negated collexemes for tak is of the [ter-X-kan] schema. In contrast, none of the top-20 distinctive negated collexemes for tidak in Table 12 below occur in the [ter-X-kan] schema; in fact, the [ter-X-kan] collexemes in Table 11 are those strongly indistinctive for tidak. The majority (i.e., $65 \%$ ) of the top-20 distinctive negated collexemes of tidak are in the active voice schema with 
[me-X-kan]. The following code shows the use of dist.for.A() to output the top-20 most distinctive collexemes for tidak (i.e., the construction A).

\# retrieve the top-20 most distinctive negated-collexems for 'tidak'

dist.for.A(dca.out = tidaktak.dca, top.n $=20$ )

Table 12 Top-20 distinctive negated collexemes for tidak

\begin{tabular}{|c|c|c|c|c|c|c|c|}
\hline & predi & gloss & tidak & tak & assoc & p.fye & collstr \\
\hline 1 & melakukan & to do & 669 & 44 & $A>B$ & $4.93 e-13$ & 12.31 \\
\hline 2 & menimbulkan & to cause to & 271 & 12 & $A>B$ & $1.23 \mathrm{e}-08$ & 7.91 \\
\hline 3 & dilakukan & to be done & 314 & 17 & $A>B$ & $2.83 e-08$ & 7.55 \\
\hline 4 & menggunakan & to $\mathrm{u}$ (tili)se & 299 & 20 & $A>B$ & $2.35 \mathrm{e}-06$ & 5.63 \\
\hline 5 & memberikan & to give & 506 & 51 & $A>B$ & $6.47 \mathrm{e}-05$ & 4.19 \\
\hline 6 & melaksanakan & to carry & 70 & 2 & $A>B$ & $1.03 \mathrm{e}-03$ & 2.99 \\
\hline 7 & menaikkan & to raise & 52 & 1 & $\mathrm{~A}>\mathrm{B}$ & $2.37 \mathrm{e}-03$ & 2.62 \\
\hline 8 & dibenarkan & to be & 71 & 3 & $A>B$ & -03 & 2.4 \\
\hline 9 & ditemukan & to be & 229 & 23 & $\mathrm{~A}>\mathrm{B}$ & $6.33 e-03$ & 2.20 \\
\hline 10 & merugikan & to $\mathrm{adv}$ & 81 & 5 & $\mathrm{~A}>\mathrm{B}$ & $9.72 \mathrm{e}-03$ & 2.0 \\
\hline 11 & menjalankan & to ca & 60 & 3 & $\mathrm{~A}>\mathrm{B}$ & -02 & 1.8 \\
\hline 12 & mendapatkan & to rece & 286 & 33 & $\mathrm{~A}>\mathrm{B}$ & $1.59 \mathrm{e}-02$ & 1.80 \\
\hline 13 & dimanfaatkan & to be $n$ & 65 & 4 & $A>B$ & $2.04 \mathrm{e}-02$ & 1.6 \\
\hline 14 & menjanjikan & to be $\mathrm{p}$ & 24 & 0 & $A>B$ & $2.29 \mathrm{e}-02$ & 1.6 \\
\hline 15 & dilaksanakan & to be & 71 & 5 & $A>B$ & $2.66 \mathrm{e}-02$ & 1.5 \\
\hline 16 & diperbolehkan & to be : & 133 & 13 & $\mathrm{~A}>\mathrm{B}$ & $2.82 \mathrm{e}-02$ & 1.5 \\
\hline 17 & menyebabkan & to cau & 34 & 1 & $\mathrm{~A}>\mathrm{B}$ & $2.82 \mathrm{e}-02$ & 1.5 \\
\hline 18 & menetapkan & to determ & 22 & 0 & $A>B$ & $3.13 e-02$ & 1.5 \\
\hline 19 & memberatkan & to (be) burden(some) & 33 & 1 & $\mathrm{~A}>\mathrm{B}$ & $3.22 \mathrm{e}-02$ & 1.4 \\
\hline 20 & dijadikan & to be used as & 51 & 3 & $A>B$ & $3.54 \mathrm{e}-02$ & 1.4 \\
\hline
\end{tabular}

The results of DCA refine our previous finding in Section 4.3 regarding the association of tak with the static-passive [ter-X-kan] schema. In this paper, we showed that not only tak has relatively higher number of [ter-X-kan] predicates (i.e., the type frequency of the schema) than expected by chance in comparison to the other two schemas and to tidak, but also it has strong association with a set of [ter-X-kan]-specific predicates in its usage occurrences (i.e., tak's token frequencies) with these predicates. The distinctive negated collexemes in Table 11 and Table 12 offer more detailed usage-based data on how the two negations are used in a set of statistically-based, entrenched collocations in a natural language setting, especially in a written mode such as online news. In turn, the data can be instrumental, among others, for teaching Indonesian to foreign learners in helping them to reach a native-like performance when using a negation in its distinctive collocational patterns.

\section{CONCLUSION}

In this paper, we have illustrated the use of $\mathrm{R}$ in conducting a series of quantitative corpus-based analyses on Indonesian Negating Constructions. We found that tidak is the most frequent form occurring in a 17,942,268 million-word online news corpus (Section 4.1). Then, we identified significant differences, but with moderate effect, between the two most frequent negations, namely tidak and tak, in terms of the type frequencies of three negated-predicate schemas, 
namely [me-X-kan], [di-X-kan], and [ter-X-kan] (Section 4.3). The clear effect emerging from the data is the significant association between tak and the [ter-X-kan] schema, which is relatively not the case for tidak (cf., e.g., Figure 5). Our corpus-based finding provides a quantitative nuance to Sneddon et al's (2010, p. 203) hypotheses, stating that (i) tidak is common for negating ter-predicates in present-day Indonesian, and (ii) the preference of tak for ter-verbs is a past conventional usage; what we found instead is that while tidak does negate predicates immediately following it in [ter-X-kan] schema, this usage is relatively more associated with tak even in the present-day Indonesian. Yet, practical relevance of such effect might not be that substantial (note the moderate Cramer's $V$ measure of this analysis). Lastly, we have introduced a quantitative technique called Distinctive Collexeme Analysis (DCA) and demonstrated how it can be computed in R (Section 4.4). We applied DCA to measure a more fine-grained level of usage differentiating tidak and tak, namely their verb-specific preferences. The results of DCA have shown that tak in its usage tokens predominantly collocates with certain [ter-X-kan] predicates, which are in turn strongly repelled by tidak (Table 11); this can enrich our initial finding on the association of the schema with tak. We also pointed out a potential implication of these distinctive collocational data for foreign learners of Indonesian.

We acknowledge, however, that our results are limited, in terms of the corpus, focused constructional schemas, and the design of the searching patterns (i.e., regexes) in extracting the collocations. We hope further studies can replicate and broaden our work with different corpus genre of potentially larger size and with wider analytical scopes. A potential follow-up from this study, especially in relation to the findings of DCA, is to determine the extent to which the occurrences of particular predicates in a negating construction are predictive for the presence of tak versus tidak as the negating forms, and vice versa; this can be measured using the Delta $\mathrm{P}$ $(\Delta P)$ statistics (cf., Gries, 2013a; Levshina, 2015, pp. 232, 234). After all, this paper reveals only the tip of the R-iceberg, especially for performing quantitative corpus linguistics. Be that as it may, in the remainder of this section, we intend to summarise our thoughts about, at least, two reasons why it is worth investing the time to explore the world of $\mathrm{R}$ for corpus linguistics.

The first reason is the nature of $\mathrm{R}$ as a programming language. As a programming language, $\mathrm{R}$ allows its users to create their own programs/functions to perform whatever operations they could imagine in relation to processing and analysing corpus data. This versatility of $\mathrm{R}$ means that users are no longer tied to the limitations of some other commercial or free corpus linguistic tools for performing certain tasks, in the sense that when a given corpus linguistic software cannot do X, neither can the users. Readers can relate this argument, for instance, to what we did for performing DCA, and to the other all-in-one statistical and textprocessing analyses showcased in this paper. The second reason is the well-tailored ecology offered by RStudio and R Markdown notebook for the unified and more reproducible research workflows with R. These run the gamut of importing the (raw) data, (pre-)processing the data, analysing the data into insights, and finally communicating the results into a report, as embodied in this paper. In our view, these integrated features of $\mathrm{R}$ and its powerful computational tools, among others, take us to the cutting-edge of data science in corpus linguistics. 


\section{REFERENCES}

Anthony, L. (2014). AntConc (Version 3.4.3). Tokyo, Japan: Waseda University. Retrieved from http://www.laurenceanthony.net

Arka, I. W. (2010, August). Dynamic and stative passives in Indonesian \& their computational implementation. Paper presented at the MALINDO Workshop, Jakarta: Paper.

Baayen, R. H. (2008). Analyzing linguistic data: A practical introduction to statistics using $R$. Cambridge, UK ; New York: Cambridge University Press.

Biemann, C., Heyer, G., Quasthoff, U., \& Richter, M. (2007). The Leipzig Corpora Collection: Monolingual corpora of standard size. In M. Davies, P. Rayson, S. Hunston, \& P. Danielsson (Eds.), Proceedings of the Corpus Linguistics Conference. University of Birmingham, UK. Retrieved from http://ucrel.lancs.ac.uk/publications/CL2007/paper/190_Paper.pdf

Desagulier, G. (2017). Corpus linguistics and statistics with R: Introduction to quantitative methods in linguistics. New York, NY: Springer Berlin Heidelberg.

Diessel, H. (2015). 14. Usage-based construction grammar. In E. Dabrowska \& D. Divjak (Eds.), Handbook of Cognitive Linguistics (pp. 296-322). Berlin ; Boston: De Gruyter Mouton.

Dinakaramani, A., Rashel, F., Luthfi, A., \& Manurung, R. (2014). Designing an Indonesian part of speech tagset and manually tagged Indonesian corpus. In 2014 International Conference on Asian Language Processing (IALP) (pp. 66-69). doi:10.1109/IALP.2014.6973519

Flanagan, J. (2017). Reproducible research: Strategies, tools, and workflows. Studies in Variation, Contacts and Change in English, 19. Retrieved from http://www.helsinki.fi/varieng/series/volumes/19/flanagan/

Goldberg, A. E. (1995). Constructions: A construction grammar approach to argument structure. Chicago: University of Chicago Press.

Goldberg, A. E. (2006). Constructions at work: The nature of generalization in language. Oxford: Oxford University Press.

Goldhahn, D., Eckart, T., \& Quasthoff, U. (2012). Building large monolingual dictionaries at the Leipzig Corpora Collection: From 100 to 200 languages. In Proceedings of the $8^{\text {th }}$ Language Resources and Evaluation Conference (LREC) 2012 (pp. 759-765). Istanbul. Retrieved from http://www.lrec-conf.org/proceedings/lrec2012/pdf/327_Paper.pdf

Gries, S. T. (2009a). Quantitative corpus linguistics with R: A Practical Introduction. New York: Routledge.

Gries, S. T. (2009b). Statistics for linguistics with R: A practical introduction. Berlin: Mouton de Gruyter.

Gries, S. T. (2012). Collostructions. In P. J. Robinson (Ed.), The Routledge encyclopedia of second language acquisition (pp. 92-95). London: Routledge. 
Gries, S. T. (2013a). 50-something years of work on collocations: What is or should be next .... International Journal of Corpus Linguistics, 18(1), 137-166. doi:10.1075/ijcl.18.1.09gri

Gries, S. T. (2013b). Corpus linguistics: Quantitative methods. In C. A. Chapelle (Ed.), The Encyclopedia of Applied Linguistics (Vols. 1-10, pp. 1380-1385). Chichester, West Sussex, UK: Blackwell Publishing Ltd. doi:10.1002/9781405198431.wbeal0258

Gries, S. T. (2013c). Statistics for linguistics with $R$ : A practical introduction $\left(2^{\text {nd }}\right)$. Berlin: Mouton de Gruyter.

Gries, S. T. (2014). Coll.Analysis 3.5. A script for $R$ to compute perform collostructional analysis. Retrieved from http://www.linguistics.ucsb.edu/faculty/stgries/teaching/groningen/readme.txt

Gries, S. T., \& David, C. V. (2007). This is kind of / sort of interesting: Variation in hedging in English. Towards Multimedia in Corpus Studies, 2. Retrieved from http://www.helsinki.fi/varieng/journal/volumes/02/gries_david/

Gries, S. T., \& Stefanowitsch, A. (2004). Extending collostructional analysis: A corpus-based perspective on 'alternations'. International Journal of Corpus Linguistics, 9(1), 97-129.

Gries, S. T., Hampe, B., \& Schönefeld, D. (2005). Converging evidence: Bringing together experimental and corpus data on the association of verbs and constructions. Cognitive Linguistics, 16(4), 635-676.

Hilpert, M. (2006). Distinctive collexeme analysis and diachrony. Corpus linguistics and linguistic theory, 2(2), 243-256.

Hilpert, M. (2014). Collostructional analysis: Measuring associations between constructions and lexical elements. In D. Glynn \& J. A. Robinson (Eds.), Corpus methods for semantics: Quantitative studies in polysemy and synonymy (pp. 391-404). Amsterdam: John Benjamins Publishing Company.

Janda, L. A. (2013). Quantitative methods in Cognitive Linguistics: An introduction. In L. A. Janda (Ed.), Cognitive linguistics: The quantitative turn (pp. 1-32). Berlin: Mouton de Gruyter.

Janda, L. A., \& Lyashevskaya, O. (2013). Semantic profiles of five Russian prefixes: Po-, s-, Za-, Na-, Pro-. Journal of Slavic Linguistics, 21(2), 211-258. doi:10.1353/js1.2013.0012.

Kroeger, P. (2014). External negation in Malay/Indonesian. Language, 90(1), 137-184. doi:10.1353/lan.2014.0000.

Larasati, S. D., Kuboň, V., \& Zeman, D. (2011). Indonesian Morphology Tool (MorphInd): Towards an Indonesian Corpus. In Systems and Frameworks for Computational Morphology (pp. 119-129). Springer, Berlin, Heidelberg. doi:10.1007/978-3-64223138-4_8.

Levshina, N. (2015). How to do Linguistics with R: Data exploration and statistical analysis. John Benjamins Publishing Company. 
R Core Team. (2017). R: A language and environment for statistical computing. R Foundation for Statistical Computing, Vienna, Austria. Retrieved from http://www.R-project.org/

Sanchez, G. (2013). Handling and processing strings in $R$. Berkeley: Trowchez Editions. Retrieved from http://www.gastonsanchez.com/Handling and Processing Strings in R.pdf

Sneddon, J. N. (2006). Colloquial Jakartan Indonesian. Canberra, Australia: Pacific Linguistics, Research School of Pacific and Asian Studies, The Australian National University.

Sneddon, J. N., Adelaar, A., Djenar, D. N., \& Ewing, M. C. (2010). Indonesian reference grammar $\left(2^{\text {nd }}\right)$. Crows Nest, New South Wales, Australia: Allen \& Unwin.

Stefanowitsch, A. (2005). The function of metaphor: Developing a corpus-based perspective. International Journal of Corpus Linguistics, 10(2), 161-198. doi:10.1075/ijcl.10.2.03ste

Stefanowitsch, A. (2013). Collostructional analysis. In T. Hoffmann \& G. Trousdale (Eds.), The Oxford handbook of Construction Grammar. Oxford: Oxford University Press. doi:10.1093/oxfordhb/9780195396683.013.0016

Stefanowitsch, A. (2014). Collostructional analysis: A case study of the English into-causative. In T. Herbst, H.-J. Schmid, \& S. Faulhaber (Eds.), Constructions collocations patterns. Berlin ; Boston: Walter De Gruyter, GmbH.

Stefanowitsch, A., \& Gries, S. T. (2003). Collostructions: Investigating the interaction of words and constructions. International Journal of Corpus Linguistics, 8(2), 209-243.

Stefanowitsch, A., \& Gries, S. T. (2009). Corpora and grammar. In A. Lüdeling \& M. Kytö (Eds.), Corpus linguistics: An international handbook (Vol. 2, pp. 933-951). Berlin: Mouton de Gruyter.

Wickham, H., \& Grolemund, G. (2017). $R$ for Data Science. Canada: O'Reilly. Retrieved from http://r4ds.had.co.nz/

1 The writing of this paper is supported by (i) the Monash International Postgraduate Research Scholarships (MIPRS) and the Monash Graduate Scholarships (MGS) (awarded to Gede Primahadi Wijaya Rajeg) as well as by the MonARCH High Performance Computing cluster at Monash University, Australia; and by (ii) the Indonesian Endowment Fund for Education (LPDP) (awarded to Karlina Denistia).

${ }^{2}$ Data science here is not intended to be a buzz word, but a scientific enterprise about how "to turn raw data into understanding, insight, and knowledge" (Wickham \& Grolemund, 2017, p. ix).

${ }^{3}$ It should also be mentioned that there is a great free corpus linguistic software, namely AntConc, that can do most of the core corpus linguistic analyses (e.g., creating concordances, frequency lists, collocational analyses, etc.) (cf., Anthony, 2014).

${ }^{4}$ The term construction here is understood as form-meaning pairing as in the Construction Grammar approach (cf., Diessel, 2015; Goldberg, 1995, 2006, inter alia).

${ }^{5}$ The text is a chunk of a short story entitled Darojat dan Istrinya 'Darojat and his wife' written by Budi Darma. The story was published in Jawa Pos and we scrapped the text with $\mathrm{R}$ from https://lakonhidup.wordpress.com/2016/07/17/darojat-dan-istrinya/ on 3 September 2016 at 12.19 PM.

${ }^{6}$ Download Indonesian POS Tagger from https://github.com/andryluthfi/indonesian-postag. For running the POS Tagger, users are also required to install MorphInd (Larasati, Kuboň, \& Zeman, 2011). Details information on MorphInd, including how to download and install it, can be found at http://septinalarasati.com/morphind/.

${ }^{7}$ https://cran.r-project.org 


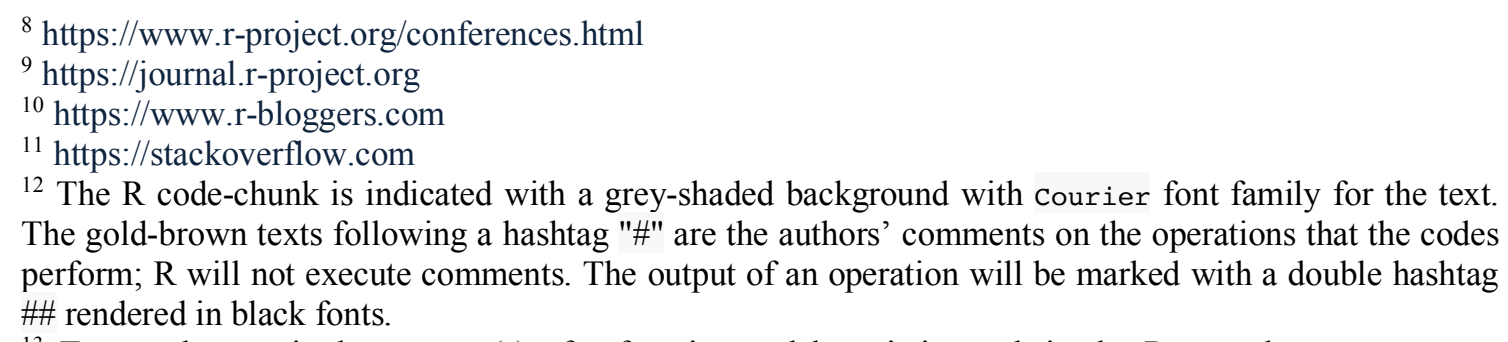
${ }^{13}$ To see the required argument(s) of a function and how it is used, in the R console, one can type question mark (?) followed by the name of the function. For instance, typing ?round() will open up a window showing the documentation and details of the round() function.

${ }^{14}$ Download RStudio from https://www.rstudio.com/products/rstudio/download/. R has to be installed before installing RStudio.

${ }^{15} \mathrm{R}$ Markdown is an $\mathrm{R}$ package that can be installed by running install.packages ( "rmarkdown") (but cf. Wickham \& Grolemund, 2017, p. 424). For details, see also http://rmarkdown.rstudio.com/index.html.

${ }^{16} \mathrm{http}: / /$ rmarkdown.rstudio.com/r notebooks.html

${ }^{17}$ For introductions to working with $\mathrm{R}$ Markdown for MS Word output, see http://rmarkdown.rstudio.com/word document_format.html and http://rmarkdown.rstudio.com/articles_docx.html. Readers may also explore Yihui Xie's free online-book on bookdown package for producing book via R Markdown (https://bookdown.org/yihui/bookdown/).

${ }^{18}$ The R Markdown file is made open-access with CC BY-NC-SA 4.0 licence on our figshare webpages: https://figshare.com/articles/Working_with_a_linguistic_corpus_using_R_An_introductory_note_with_In donesian_Negating_Construction/5873256.

${ }^{19}$ Download Leipzig Corpora from http://wortschatz.uni-leipzig.de/en/download/.

${ }^{20} \mathrm{Perl}$ is another kind of programming language.

21 There is a faster alternative to the combination of gregexpr() and regmatches(). It is the str_extract_all() function from the stringr package, which can be installed as part of the coherent family of packages called the tidyverse (cf., Wickham \& Grolemund, 2017, for a comprehensive introduction to the tidyverse packages; further details of the tidyverse can also be found at https://www.tidyverse.org). We do not use str_extract_all() and any other functions from the core tidyverse packages to familiarise readers with what the base $\mathrm{R}$ can offer to the tasks at hand. Once the readers feel comfortable with the base $\mathrm{R}$, we do encourage readers to advance to the tidyverse, which has been very popular among the majority of the $\mathrm{R}$ communities.

${ }^{22}$ The underlying design for this analysis is adapted from a study by Janda and Lyashevskaya (2013) that contrasts the semantics of five aspectual prefixes in Russian according to the number of the verbs tagged with a set of lexico-semantic classes that are prefixed with one of the five aspectual prefixes.

${ }^{23}$ The non-scientific equivalent of the $p$-value of $1.929 \mathrm{e}-15$ is 0.000000000000001929177 .

${ }^{24}$ A stricter practice is to use fisher.test() rather than chisq.test() when none of the expected frequencies in the table are larger than five. When we submit the tak.tidak.xtab data into fisher.test, the result is still significant as produced by the chi-square test since the $p$-value is below the standard threshold of 0.05 (i.e. $p=3.683827 \mathrm{e}-10$ ). Run the following line in $\mathrm{R}$ console fisher.test (tak.tidak.xtab) \$p.value to get the p-value.

${ }^{25}$ Cramer's $V$ value is a measure of the size of effect found in a contingency table larger than 2-by-2 table, as in the case of our negation data (Levshina, 2015, p. 217). Cramer's $V$ value is not affected by the sample size, unlike the $p$-value. The range of the Cramer's $V$ value spans from 0 (no effect/no correlation) to 1 (large effect/perfect correlation) (cf., Levshina, 2015, p. 209). The code for the Cramer's $V$ value in this paper is sqrt(taktidak.chisq\$statistic/sum(tak.tidak.xtab)*(min(dim(tak.tidak.xtab))1)) (cf. Gries, 2013c, p. 186).

${ }^{26}$ See Gries (2013b, p. 1381) for the use of the dhyper () function in $\mathrm{R}$ as an alternative to perform a onetailed FYE test.

${ }^{27}$ See the Youtube video featuring Laura A. Janda entitled The use of statistics in Cognitive Linguistics on her presentation slide at 28:39-28:45 minutes (https://www.youtube.com/watch? $\mathrm{v}=1 \mathrm{CJw}-\mathrm{Qd} 3 \mathrm{ZZg}$ ).

${ }^{28}$ See Levshina (2015, p. 245) for the idea of reference construction in DCA, as well as Gries (2013b, p. 1381) for how the frequency deviation in a reference construction affects the computation of the onetailed FYE. 
29 The R code for our dist.coll () function is embedded in the R Markdown document of this paper. The core FYE computation in dist.coll() is adapted from Levshina's (2015, p. 245) pv.Fisher.collstr(). We customised our function with options to compute one- or two-tailed FYE by specifying the value of the alternative argument for the embedded fisher.test() function; in Levshina's pv.Fisher.collstr(), the alternative argument is set to the default "two.sided" test. In addition, our dist.coll() function returns a data-frame object (cf. Table 11 and Table 12, minus the gloss) that can be directly processed in R console. There is also a well-known R script, namely Coll.Analysis 3.5 (Gries, 2014), that can perform all of the Collostructional Analysis family of methods and that prints out the results either into a plain text format or into the $\mathrm{R}$ console screen.

${ }^{30}$ The gloss column is not part of the output because it is manually added by the authors. 